\title{
Neurotoxicity and underlying cellular changes of 21 mitochondrial respiratory chain inhibitors
}

\author{
Johannes Delp ${ }^{1,2}$. Andrea Cediel-Ulloa ${ }^{3,10}$. Ilinca Suciu ${ }^{1,4}(1) \cdot$ Petra Kranaster ${ }^{1,4}$ - Barbara MA van Vugt-Lussenburg ${ }^{5}$. \\ Vesna Munic Kos ${ }^{3,11}$. Wanda van der Stel ${ }^{6}$. Giada Carta ${ }^{7}$. Susanne Hougaard Bennekou ${ }^{8} \cdot$ Paul Jennings $^{7}$. \\ Bob van de Water ${ }^{6} \cdot$ Anna Forsby $^{3,9} \cdot$ Marcel Leist $^{1}$
}

Received: 16 November 2020 / Accepted: 29 December 2020 / Published online: 29 January 2021

(c) The Author(s) 2021

\begin{abstract}
Inhibition of complex I of the mitochondrial respiratory chain (cI) by rotenone and methyl-phenylpyridinium (MPP +) leads to the degeneration of dopaminergic neurons in man and rodents. To formally describe this mechanism of toxicity, an adverse outcome pathway (AOP:3) has been developed that implies that any inhibitor of cI, or possibly of other parts of the respiratory chain, would have the potential to trigger parkinsonian motor deficits. We used here 21 pesticides, all of which are described in the literature as mitochondrial inhibitors, to study the general applicability of AOP:3 or of in vitro assays that are assessing its activation. Five cI, three complex II (cII), and five complex III (cIII) inhibitors were characterized in detail in human dopaminergic neuronal cell cultures. The NeuriTox assay, examining neurite damage in LUHMES cells, was used as in vitro proxy of the adverse outcome (AO), i.e., of dopaminergic neurodegeneration. This test provided data on whether test compounds were unspecific cytotoxicants or specifically neurotoxic, and it yielded potency data with respect to neurite degeneration. The pesticide panel was also examined in assays for the sequential key events (KE) leading to the AO, i.e., mitochondrial respiratory chain inhibition, mitochondrial dysfunction, and disturbed proteostasis. Data from KE assays were compared to the NeuriTox data (AO). The cII-inhibitory pesticides tested here did not appear to trigger the AOP:3 at all. Some of the cI/cIII inhibitors showed a consistent AOP activation response in all assays, while others did not. In general, there was a clear hierarchy of assay sensitivity: changes of gene expression (biomarker of neuronal stress) correlated well with NeuriTox data; mitochondrial failure (measured both by a mitochondrial membrane potential-sensitive dye and a respirometric assay) was about 10-260 times more sensitive than neurite damage (AO); cI/cIII activity was sometimes affected at $>1000$ times lower concentrations than the neurites. These data suggest that the use of AOP: 3 for hazard assessment has a number of caveats: (i) specific parkinsonian neurodegeneration cannot be easily predicted from assays of mitochondrial dysfunction; (ii) deriving a point-of-departure for risk assessment from early KE assays may overestimate toxicant potency.
\end{abstract}

\section{Article highlights}

- Comparison of 21 data-rich mitochondrial toxicants for neurotoxicity

- Quantitative comparison of key event triggering thresholds for AOP:3

- Comparison of two cell models and two exposure times for neurotoxicity

This work reflects only the authors' view and the European Commission is not responsible for any use that may be made of the information it contains.

Supplementary Information The online version contains supplementary material available at https://doi.org/10.1007/s0020 4-020-02970-5.

Marcel Leist

marcel.leist@uni-konstanz.de

Extended author information available on the last page of the article 


\section{- Comparison of transcriptome changes and classical key event measures for sensitivity}

Keywords In vitro neurotoxicity $\cdot$ Mitotoxicity $\cdot$ TempO-Seq $\cdot$ High-content imaging $\cdot$ AOP: $3 \cdot$ Mechanistic safety assessment

\begin{tabular}{|c|c|}
\hline \multicolumn{2}{|c|}{ Abbreviations } \\
\hline $\mathrm{AO}$ & Adverse outcome \\
\hline $\mathrm{AOP}$ & Adverse outcome pathway \\
\hline ATP & Adenosine triphosphate \\
\hline cAMP & $\begin{array}{l}\text { N6,2'-O-dibutyryladenosine 3',5'-cyclic } \\
\text { monophosphate }\end{array}$ \\
\hline $\mathrm{cI}-\mathrm{V}$ & MRC complex I-V \\
\hline CNS & Central nervous system \\
\hline Cyt c & Cytochrome c \\
\hline ETC & $\begin{array}{l}\text { Mitochondrial electron transport chain, i.e., } \\
\text { MRC }\end{array}$ \\
\hline $\mathrm{FAD}\left(\mathrm{H}_{2}\right)$ & $\begin{array}{l}\text { Flavin adenine dinucleotide (FAD: oxidized, } \\
\text { FADH2: reduced) }\end{array}$ \\
\hline FCCP & $\begin{array}{l}\text { Carbonyl cyanide-4-(trifluoromethoxy) } \\
\text { phenylhydrazone }\end{array}$ \\
\hline GDNF & Glial-derived neurotrophic factor \\
\hline KE & Key event \\
\hline KER & Key event relationship \\
\hline MIE & Molecular initiating event \\
\hline MoA & Mode of action \\
\hline MPP & 1-Methyl-4-phenylpyridinium \\
\hline MRC & Mitochondrial respiratory chain \\
\hline NA & Neurite area \\
\hline $\mathrm{NAD}(\mathrm{H})$ & $\begin{array}{l}\text { Nicotinamide adenine dinucleotide (NAD: } \\
\text { oxidized, NADH: reduced) }\end{array}$ \\
\hline $\mathrm{O}_{2}$ & Oxygen \\
\hline OCR & Oxygen consumption rate \\
\hline Q & Ubiquinone or coenzyme $\mathrm{Q}$ \\
\hline ROS & Reactive oxygen species \\
\hline TCA & $\begin{array}{l}\text { Citric acid cycle or Krebs cycle or tricarbox- } \\
\text { ylic acid cycle }\end{array}$ \\
\hline $\mathrm{V}$ & Viability \\
\hline
\end{tabular}

\section{Introduction}

While there are many known mitochondrial toxicants, it is unclear whether they all lead to the same adverse outcomes (AO) in the nervous system. The concept of adverse outcome pathways (AOP) was established to link modifications of biological processes on a molecular/mechanistic level with an AO in humans (Leist et al. 2017). It is generally assumed that a molecular initiating event (MIE) leads to the AO by a series of key events (KE) (Allen et al. 2014). For the establishment of an AOP, the weight of evidence linking the KEs with each other needs to be assessed, quantified/rated, and documented in form of key event relationships (KER).
An important feature of AOPs is that they are "chemically agnostic", i.e., they do not describe modes-of-actions (MoA) of defined chemicals, but rather outline biological/pathophysiological processes (Bal-Price et al. 2017; Delrue et al. 2016; Vinken 2013; Zhou 2015). For example, the KE "inhibition of mitochondrial respiratory chain complex I (cI)" describes the cellular process, and not the relevant toxicant. However, each AOP definition also includes example chemicals that would trigger the respective AOP, given that they reach a sufficiently high concentration at the target of the MIE. KER are also often established on the basis of known example toxicants (Bal-Price et al. 2018; Terron et al. 2018), and most AOPs in the AOP Wiki (https://aopwiki.org/) have been established and exemplified by mining the existing literature. This means that the evidence was collected from heterogeneous sources in the scientific literature. Such studies were not designed originally to support building an AOP, and there are only very few recent examples of AOPs that are based on dedicated research to build the AOP and to parameterize KERs (Browne et al. 2015, 2017; Gijbels et al. 2020; Pistollato et al. 2020; Spinu et al. 2019).

The AOP:3 "Inhibition of the mitochondrial complex I of nigrostriatal neurons leads to parkinsonian motor deficits" describes how the binding to (MIE) and inhibition of mitochondrial cI (KE1) lead to mitochondrial dysfunction (KE2), impairment of proteostasis (KE3), degeneration of dopaminergic neurons in the substantia nigra (KE4), neuroinflammation (KE5), and, finally, parkinsonian motor symptoms (AO) (Fig. 1) (Bal-Price et al. 2018; Terron et al. 2018). AOP: 3 is one of the few AOPs fully endorsed by the OECD, demonstrating a high level of documentation, assessment of evidence, and formalization. However, it was not the result of prospective research. Rather, the evidence was assembled post hoc. Therefore, it is not clear whether each compound capable of binding to cI would trigger AOP:3. Rotenone and MPP +, for which comprehensive studies were available, including mechanistic research and human data, have been used as main examples for AOP:3. On this basis, mechanistic plausibility could be demonstrated for epidemiological observations (Ockleford et al. 2017). Notably, the AOP:3 has particular features on both ends: i) the binding of known inhibitors to cI (MIE) always leads to inhibition of the complex (Sherer et al. 2007; Troger et al. 2020). Therefore, inhibition measurements can be used to also characterize the MIE (binding event). ii) In a regulatory context, the death of dopaminergic neurons (KE4) would be acceptable in animal studies as adverse outcome. Thus, this 

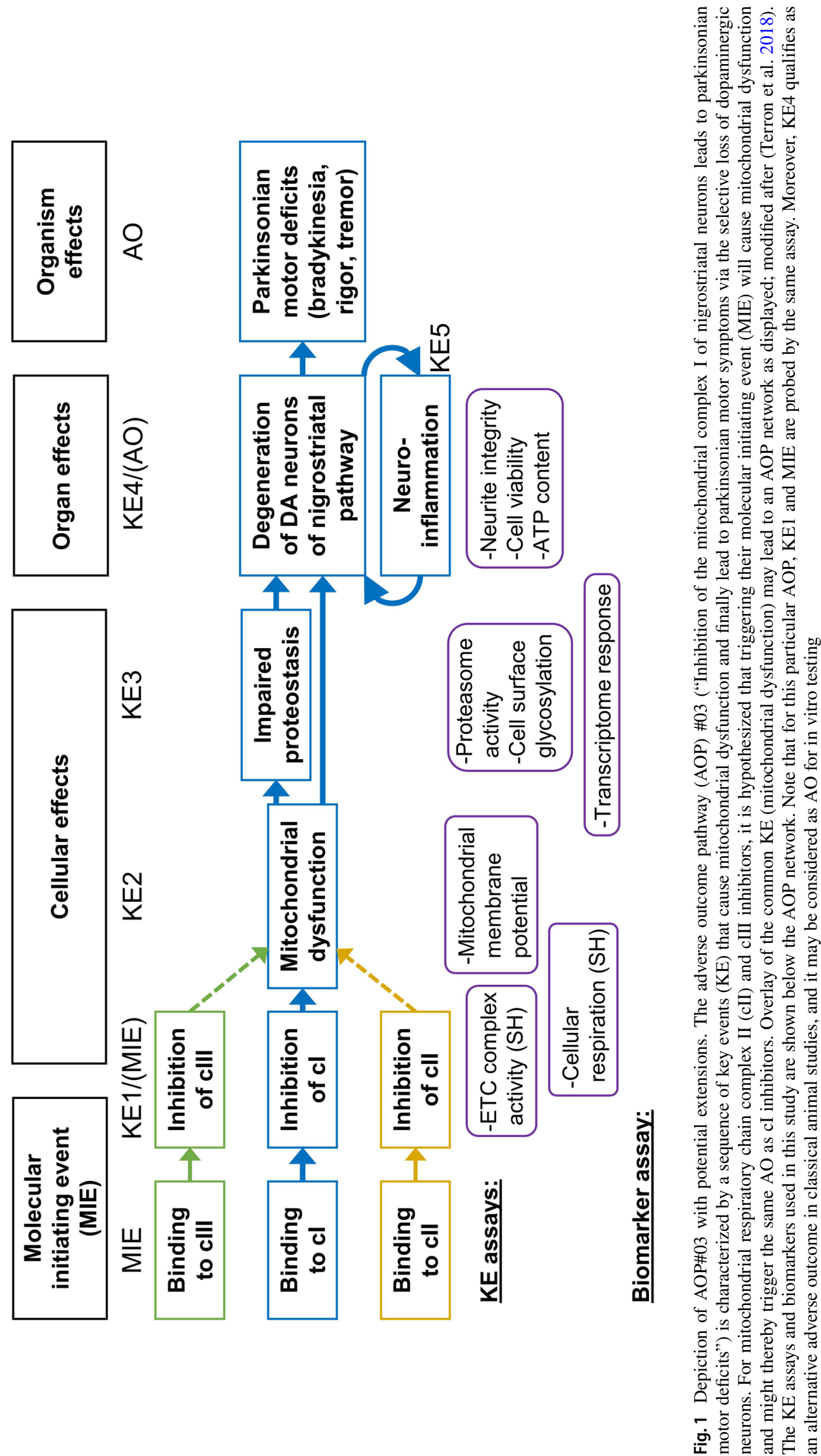
specific neurodegeneration can be used as an alternative $\mathrm{AO}$ in vitro, and it is experimentally easier accessible than the "final" AO of parkinsonian motor deficits.

The mitochondrial respiratory chain (MRC) channels electrons from nutritional substrates (e.g., carbohydrates/ sugars, fatty acids or amino acids) to establish a proton gradient across the inner mitochondrial membrane (IMM). Two independent entry points for the electrons into the MRC exist: complex I (cI; NADH:ubiquinone oxidoreductase) and cII (succinate dehydrogenase; oxidation of $\mathrm{FADH}_{2}$ ). Both complexes transfer their electrons to coenzyme Q10 which delivers them to cIII $\left(\mathrm{CoQH}_{2}\right.$-cytochrome c reductase) (van der Bliek et al. 2017). From there, the electrons flow via cytochrome c to cIV (cytochrome c oxidase), where they are finally transferred to oxygen to form water. Only complexes I, III, and IV, but not cII, translocate protons across the IMM. This proton gradient is used by $\mathrm{cV}$ (ATP synthase) to synthesize ATP (Rich 2003).

If assessed in animal models, mitochondrial toxicity is predicted with low sensitivity, most likely due to the fact that young and healthy animals are used, which have high compensatory capacities, so that often other adversities are observed at doses below those allowing the detection of mitochondrial toxicity. Drugs targeting the mitochondrial respiratory chain (MRC) are relatively well tolerated in normal tissues (Blecha et al. 2017). Many in vitro studies may also be insensitive to mitochondrial toxicants as cells are kept in supra-physiological (e.g., 3-5 times higher than normal plasma levels) glucose concentrations (Blomme and Will 2016; Broom et al. 2016; Perron et al. 2013; Tilmant et al. 2018).

To assess the consequences of mitochondrial impairment by potential environmental toxicants, we searched for commercially available mitochondrial cI-cIII inhibitors within the use class of pesticides (and pesticide-analogs) (Suppl. Figure 1). In the context of the European Research project EU-ToxRisk (Daneshian et al. 2016; Escher et al. 2019; Graepel et al. 2019), a set of 21 compounds was used to establish assays for mitochondrial respiratory chain functionality in neurons (Delp et al. 2019) and for testing in different non-neuronal cell systems (representing liver and kidney) (van der Stel et al. 2020). It could not be clarified in these studies, how the different modes of mitochondrial respiratory chain inhibition related to (or predicted) dopaminergic neurotoxicity, and how different assays of AOP:3 key events were correlated. To address this question, we used LUHMES and SH-SY5Y cells.

Using these models, we asked whether all KE assays gave similar inhibitor potency predictions. We hypothesized that earlier KEs may be more sensitive, and that higher concentrations were needed to trigger later $\mathrm{KE}$, because more cellular mechanisms of adaptation and counter-regulation have to be overcome. This is to our knowledge the first dedicated study that used a broad set of chemicals triggering a neuronal AO and then following its effects along the AOP KEs. We addressed the important question, in how far early KE data can and will predict an AO. We assessed dopaminergic neurodegeneration (as $\mathrm{AO}$ ), and determined the respective inhibitor potencies. From this, we worked backwards through the chain of KEs toward the KE1 (which is here overlapping with the MIE).

\section{Materials and methods}

\section{Materials}

Unless specified otherwise, cell culture reagents (consumables and media) were from Gibco/Thermo Fisher Scientific (Waltham, USA), and fine chemicals (inhibitors, substrates) were from Sigma-Aldrich (Steinheim, GER). CAS identifiers of the tested set of chemicals are compiled in Suppl. Fig. 1.

\section{Determination of cytotoxicity in U20S cells}

Cytotoxicity was determined in the Cytotox CALUX assay as follows (as also described in DB-ALM protocol 197). A cell suspension of 100,000 cells $/ \mathrm{ml}$ was prepared in assay medium, and white 384-well plates were filled with $30 \mu \mathrm{l} /$ well cell suspension. Twenty-four hours after seeding, a dilution series of test compound, as well as positive and negative controls, were added to the cells. After $24 \mathrm{~h}$ exposure, the medium was removed, and $10 \mu \mathrm{l}$ of Triton X-100 lysis buffer was added to each well. The luminescent signal was determined in a luminometer by injecting BDS Illuminate Mix and measuring the light emission. The Cytotox CALUX cell line constitutively expresses a high level of luciferase protein; the light emission is therefore proportional to the cell number of live cells, and its decrease can be used as measure of cytotoxicity. The light emission generated by cells exposed to vehicle control was set to $100 \%$, and the luminescence of cells exposed to the positive control toxicant tributyltin acetate $[100 \mu \mathrm{M}]$ was set to $0 \%$. The light output of the cells exposed to different concentrations of test compounds was scaled accordingly.

\section{SH-SY5Y cell culture and differentiation}

SH-SY5Y cells originate from the bone marrow biopsy of a young neuroblastoma case (ATCC CRL-2266). The cells are able to form neurites and display several dopaminergic characteristics. For this reason, they are frequently used in neuropathology and neurotoxicity research (Cheung et al. 2009; Forsby et al. 2009; Gustafsson et al. 2010; Lopes et al. 2010; Nordin-Andersson et al. 2003; Okuda et al. 2006; Xie 
et al. 2010). Cells were plated in $100 \mu$ proliferation medium (EMEM supplemented with $10 \%$ fetal bovine serum, $2 \mathrm{mM}$ L-glutamine, $1 \%$ non-essential amino acids, $100 \mu \mathrm{g} / \mathrm{ml}$ streptomycin and $100 \mathrm{U} / \mathrm{ml}$ penicillin) at $37{ }^{\circ} \mathrm{C}$ in a $5 \% \mathrm{CO}_{2} / 95 \%$ air atmosphere (Gustafsson et al. 2010). Differentiation was initiated $24 \mathrm{~h}$ later (on day $0, \mathrm{~d} 0$ ) by exchange to $100 \mu \mathrm{l} /$ well differentiation medium (DMEM:F12, supplemented with $1 \mu \mathrm{M}$ all-trans retinoic acid (RA), $1 \times \mathrm{N} 2$ supplement, $2 \mathrm{mM}$ L-glutamine, $100 \mu \mathrm{g} / \mathrm{ml}$ streptomycin, and $100 \mathrm{U} / \mathrm{ml}$ penicillin). All media and supplements were obtained from Gibco (ThermoFisher) except from RA (Sigma).

\section{Neurite degeneration and cytotoxicity assessment using SH-SY5Y cells}

Cells were plated in black 96-well CELLSTAR ${ }^{\circledR}$ plates with micro-clear bottom (Greiner) at a density of 23,500 cells/ $\mathrm{cm}^{2}$ and differentiated as described above. On d3, $100 \mu \mathrm{l}$ of fresh differentiation medium were added to the wells. For the $120 \mathrm{~h}$ exposure, this medium contained twice the final treatment concentration. On d6, $100 \mu \mathrm{l}$ from each well were removed, and the procedure was repeated and the cells were analyzed on $\mathrm{d} 8$. For the $24 \mathrm{~h}$ exposure, cells received an addition of $100 \mu \mathrm{l}$ pure differentiation medium on $\mathrm{d} 3$ and were treated with compounds as described above on d6 for $24 \mathrm{~h}$ before analysis. After exposure to the chemicals, $100 \mu \mathrm{l}$ per well was removed and $20 \mu \mathrm{l}$ of a stain mixture $[6 \mu \mathrm{g} / \mathrm{ml}$ calcein-AM, $60 \mu \mathrm{g} / \mathrm{ml}$ Hoechst 33,342, and $6 \mu \mathrm{M}$ propidium iodide (PI; only for $120 \mathrm{~h}$ exposures) in DMEM:F12] was added to each well to visualize cells and neurites, nuclei and dead cells, respectively. The cells were incubated with the stain mixture for $20 \mathrm{~min}$ at $37{ }^{\circ} \mathrm{C}, 5 \% \mathrm{CO}_{2}$. After incubation, $130 \mu \mathrm{L}$ of differentiation medium were added to all the wells to stop further staining of the cells. Images were obtained using ImageXpress ${ }^{\circledR}$ Micro (Molecular Devices). The cells were imaged with a $10 \times$ objective lens; the fluorescence from the calcein stained cell bodies and neurites was detected in the FITC channel (excitation $475 \pm 34 \mathrm{~nm}$, emission $536 \pm 40 \mathrm{~nm}$ ). Nuclei were identified on the DAPI channel (excitation $377 \pm 50 \mathrm{~nm}$, emission $447 \pm 60 \mathrm{~nm}$ ) and the PI positive cells on the Texas red channel (excitation $562 \pm 40 \mathrm{~nm}$, emission $624 \pm 40 \mathrm{~nm}$ ). The mean neurite length was calculated using the Neurite Outgrowth plug-in in the MetaXpress ${ }^{\circledR}$ Software. Outgrowths were defined as cytoplasmic prolongations with a maximum width of $2 \mu \mathrm{m}$ ( 3 pixels). The minimum outgrowth size needed to be logged as significant was defined as $15 \mu \mathrm{m}$ (23 pixels). Nuclear staining with Hoechst 33342 and PI was determined using the transfluor HT plug-in in the MetaXpress ${ }^{\circledR}$ Software. Cell viability was determined by the ratio of viable cells (PI-negative) relative to the overall cell count (Hoechst 33342-positive).

\section{LUHMES cell culture}

LUHMES cells are conditionally immortalized human neuronal precursors, which can be differentiated into dopaminergic neurons (Gutbier et al. 2018a; Scholz et al. 2011). They have been characterized extensively with regards to their sensitivity to the parkinsonian toxicant MPP + I MPTP (Harischandra et al. 2020; Pierce et al. 2018; Schildknecht et al. 2009, 2015) as well as their metabolism and transcriptome changers triggered by MPP + (Delp et al. 2018a; Krug et al. 2013b, 2014). The cells have also been used for research on neurodevelopmental disorders (Krug et al. 2013a; Matelski et al. 2020; Stiegler et al. 2011), as well as for high-throughput toxicity screenings and neuron-glia interactions (Brüll et al. 2020; Delp et al. 2018b; Efremova et al. 2015; Gutbier et al. 2018b; Tong et al. 2017; Witt et al. 2017). Cells were cultured as described earlier (Scholz et al. 2011). In brief, the proliferation culture was maintained in PM [i.e., Adv. DMEM/F12 supplemented with $2 \mathrm{mM}$ L-glutamine, $1 \times \mathrm{N} 2$ supplement (Invitrogen), and $40 \mathrm{ng} / \mathrm{ml}$ recombinant human basic fibroblast growth factor ( $\mathrm{R}+\mathrm{D}$ systems)] at $37{ }^{\circ} \mathrm{C}$ in a humidified $5 \%$ $\mathrm{CO}_{2} / 95 \%$ air atmosphere. Cells were passaged every other day using $0.05 \%$ trypsin/EDTA (Invitrogen). Differentiation was initiated by changing the medium to DM [Adv. DMEM/F12 supplemented with $2 \mathrm{mM}$ L-glutamine, $1 \times \mathrm{N} 2$ supplement (Invitrogen) and $1 \mathrm{mM} \mathrm{N6,2'-O-dibutyryl}$ 3',5'-cyclic adenosine monophosphate (cAMP) (SigmaAldrich), $1 \mu \mathrm{g} / \mathrm{ml}$ tetracycline (Sigma-Aldrich), and $2 \mathrm{ng} /$ $\mathrm{ml}$ recombinant human glial cell-derived neurotrophic factor (GDNF, R \& D Systems)]. Culture plastic ware (Sarstedt) was pre-coated with $50 \mu \mathrm{g} / \mathrm{ml}$ poly-L-ornithine (PLO) and $1 \mu \mathrm{g} / \mathrm{ml}$ fibronectin (Sigma-Aldrich).

\section{LUHMES differentiation and exposure schemes (i.e., NeuriTox scheme)}

The NeuriTox test was performed as previously described (Delp et al. 2018b; Krug et al. 2013a; Stiegler et al. 2011). Briefly, cells differentiated for $48 \mathrm{~h}$ were re-seeded into 96-well plates at a density of 100,000 cells $/ \mathrm{cm}^{2}$ in DM without cAMP and GDNF, and treated $1 \mathrm{~h}$ after seeding for $24 \mathrm{~h}$. Subsequently, multiple endpoints were determined, e.g., neurite outgrowth (i.e., NeuriTox test), resazurin reduction, intracellular ATP content, gene expression levels from TempO-Seq analysis, and proteasomal activity. For the $120 \mathrm{~h}$ exposure scenario, LUHMES cells were differentiated for another 3 days after reseeding before they were treated on day 5 (d5) and $\mathrm{d} 7$ by a half medium exchange. Endpoints were determined on d10 of differentiation. 


\section{LUHMES/NeuriTox test image acquisition and analysis}

Image acquisition and analysis was performed as described previously (Krug et al. 2013a; Schildknecht et al. 2013; Stiegler et al. 2011). In brief, cells were live-stained with $1 \mu \mathrm{g} / \mathrm{ml}$ Hoechst $\mathrm{H}-33342$ and $1 \mu \mathrm{M}$ calcein-AM and image acquisition was done by an automated high content imager (Cellomics, Waltham, MA, USA). Cell viability was determined as ratio of live cells (cell bodies being Calcein- and Hoechst-positive) relative to the total amount of cells (Hoechst-positive cell bodies). Neurite area was calculated by subtracting the somatic area (Hoechst-positive area plus surrounding) from the calcein-positive area.

\section{Determination of the intracellular ATP content and resazurin reduction}

Plates from the NeuriTox test were further used after imaging for determination of alternative endpoints. Intracellular ATP was determined as described earlier (Delp et al. 2019). In brief, CellTiterGlo 2.0 assay mix (Promega) containing luciferase was added after imaging, and luminescence was recorded. For the determination of resazurin reduction, a $10 \times$ resazurin stock solution was added after imaging to the medium (final resazurin concentration $2 \mu \mathrm{g} / \mathrm{ml}$ ) (Delp et al. 2018a). After $60 \mathrm{~min}$ incubation, resazurin fluorescence was recorded (ex: $530 \mathrm{~nm}$, em: $590 \mathrm{~nm}$ ). Background-corrected data was used for further analysis.

\section{Proteasomal activity (KE3 assay)}

Activity of the proteasome was quantified as described in (Gutbier et al. 2018b). Briefly, after exposure, culture medium was replaced by assay buffer containing a cellpermeable proteasomal substrate (MeOSuc-Gly-Leu-PheAMC, $25 \mu \mathrm{M}$ (Bachem, Bubendorf, Switzerland) in HBSS). Its AMC-fluorescence (ex: $360 \mathrm{~nm}$, em: $465 \mathrm{~nm}$ ) increases with proteasomal activity and was monitored for $90 \mathrm{~min}$. Background-corrected data were used for further analysis.

\section{Detection of proteostasis impairment via NeuroGlycoTest (KE3 assay)}

The NeuroGlycoTest was performed as previously described (Kranaster et al. 2020). In brief, d6 LUHMES cells were cotreated for $6 \mathrm{~h}$ with the respiratory chain inhibitors together with $10 \mu \mathrm{M}$ azide-tagged mannosamine precursor sugar (Ac4ManNAz), synthesized according to published procedures (Saxon et al. 2002). After PBS-washing, a dibenzylcyclooctyne-PEG ${ }_{4}$-biotin (DBCO-biotin) $[100 \mu \mathrm{M}]$ (Jena
Bioscience, Jena, Germany) solution was added for $20 \mathrm{~min}$ at $37^{\circ} \mathrm{C}$ to label the incorporated azide-tagged sialic acids $(=\mathrm{SiaAz})$.

For detection of MGE-sialoproteins, cells in 6-well plates were lyzed in Laemmli buffer and boiled for $5 \mathrm{~min}$ at $95{ }^{\circ} \mathrm{C}$. After SDS-PAGE and Western blotting, membranes were probed with a goat HRP-conjugated anti-biotin antibody (Cell Signaling Technology, Massachusetts, US), with a mouse glyceraldehyde 3-phosphate dehydrogenase (GAPDH) monoclonal antibody ZG003 (Thermo Fisher Scientific, Massachusetts, US), and with a goat anti-mouse IgG horseradish peroxidase-conjugated secondary antibody. Relative band intensity was quantified using a self-developed image evaluation software. Intensities were normalized to corresponding GAPDH loading control. At least two blots from independent experiments were quantified.

For detection of neurite MGE, cells in 8-well $\mu$-slides were further incubated with a mixture of streptavidin-Alexa Fluor $488[8 \mu \mathrm{g} / \mathrm{ml}]$ (to fluorescently label the biotin-tagged sialic acids), CellTrace ${ }^{\mathrm{TM}}$ Calcein Red-Orange [10 $\left.\mu \mathrm{M}\right]$ (Thermo Fisher Scientific, Waltham, Massachusetts, US) (to visualize cellular cytoplasm), and $\mathrm{H}-33342[1 \mu \mathrm{g} / \mathrm{ml}]$ (to label nuclei) for $20 \mathrm{~min}$ at $37{ }^{\circ} \mathrm{C}$ in the dark. After PBSwashing, cells were fixed with $2 \%$ paraformaldehyde containing $4 \%$ sucrose. Microscopy was performed using a Zeiss LSM 880 point laser scanning confocal microscope. Five images were taken per condition as $\mathrm{z}$-stack (total z-range of $4 \mu \mathrm{m}$ ), and processed using Fiji. The processed images were analyzed using the SUIKER software (Karreman et al. 2019) that simultaneously, from the same image, detected and quantified viability (based on the Hoechst staining), neurite area (based on the Calcein staining) and neurite MGE sialic acids (based on the streptavidin-Alexa Fluor 488 label). Detailed descriptions of the image analysis as well as the software are freely accessible at https://invitrotox.unikonstanz.de/Suiker/.

\section{Determination of mitochondrial membrane potential and resazurin reduction in SH-SY5Y cells (KE2 assay)}

Cells were plated at a cell density of 29,500 cells $/ \mathrm{cm}^{2}$ and handled as described above for the neurite SH-SY5Y degeneration. On $\mathrm{d} 6$ of differentiation, $50 \%$ of the medium was replaced by differentiation medium containing $2 \mu \mathrm{M}$ Rhodamine 123 (ThermoFisher). After 45 min of preloading at $37{ }^{\circ} \mathrm{C}$ with $5 \% \mathrm{CO}_{2}$ in darkness, the Rhodamine 123 solution was completely removed and cells were carefully washed once with $200 \mu \mathrm{l}$ DMEM:F12. Subsequently, $50 \mu \mathrm{l}$ differentiation medium per well were added followed by the addition of $50 \mu \mathrm{l} /$ well of test compounds in medium. After $24 \mathrm{~h}$ of exposure to the test compounds, the nuclei were stained for $30 \mathrm{~min}$ with $20 \mu \mathrm{L}$ of a solution containing 
$20 \mu \mathrm{M}$ Hoechst 33342 , and the images were then acquired with a $10 \times$ objective lens using the ImageXpress ${ }^{\circledR}$ Micro (Molecular Devices) high content microplate imager. Nuclei were evaluated in the DAPI channel (excitation $377 \pm 50 \mathrm{~nm}$, emission $447 \pm 60 \mathrm{~nm}$ ), whereas Rhodamine 123 fluorescence was detected in the FITC channel (excitation $475 \pm 34 \mathrm{~nm}$, emission $536 \pm 40 \mathrm{~nm}$ ). Analysis of the Hoechst 33,342 and Rhodamine 123 fluorescence was performed using the MetaXpress ${ }^{\circledR}$ Software (Molecular Devices) with the Transfluor HT plug-in and the parameters nuclei (for Hoechst-33342) and integrated granule intensity (for Rhodamine 123). Mitochondrial membrane potential (MMP) was quantified as the total fluorescence intensity of Rhodamine 123 in relation to the number of Hoechst-stained nuclei.

For the quantification of resazurin reduction, unstained cells were treated on $\mathrm{d} 6$ as described above. After $24 \mathrm{~h}$ exposure, $150 \mu \mathrm{l}$ of the toxicant solution was removed from each well and $50 \mu \mathrm{l}$ of $88 \mu \mathrm{M}$ resazurin in DMEM:F12 medium were added (final concentration $44 \mu \mathrm{M}$ ). After $120 \mathrm{~min}$ incubation, the fluorescence intensity of reduced resazurin was recorded using a Tecan reader (ex $540 \pm 9 \mathrm{~nm}$, em $590 \pm 20 \mathrm{~nm})$.

\section{Assessment of mitochondrial respiration of intact cells (KE1/2 assay)}

Respiration of intact LUHMES cells was performed as described earlier (Delp et al. 2018a, 2019). Briefly, $48 \mathrm{~h}$ differentiated cells were re-seeded into Agilent Seahorse XFe24-well plates in DM without cAMP and GDNF at a density of 100,000 cells $/ \mathrm{cm}^{2}$ and cultured for $24 \mathrm{~h}$ before the assay was initiated. Inhibition of respiration was calculated as the difference between baseline measurements (i.e., after equilibration, last measurement before treatment) and the first measurement after treatment with the test compound. To analyze the impact on mitochondrial respiration only, nonmitochondrial respiration (retrieved by subsequent treatment with $1 \mu \mathrm{M}$ rotenone and $0.5 \mu \mathrm{M}$ antimycin $\mathrm{A}$ ) was subtracted from all values before analysis.

\section{Quantification of individual respiratory chain complexes using permeabilized LUHMES cells (MIE/ KE1 assay)}

To investigate individual respiratory chain complexes, a method developed earlier and described extensively was used (Delp et al. 2019). In brief, LUHMES cells were seeded at a density of 205,000 cells $/ \mathrm{cm}^{2}$ in PM into Agilent Seahorse XFe24-well plates. After culture for $24 \mathrm{~h}$, cells were permeabilized by replacing the medium with MAS buffer [(220 mM mannitol, $1 \mathrm{mM}$ ADP, $70 \mathrm{mM}$ sucrose, $10 \mathrm{mM}$ $\mathrm{KH}_{2} \mathrm{PO}_{4}, 5 \mathrm{mM} \mathrm{MgCl} 2,2 \mathrm{mM}$ HEPES, 1 mM EGTA, $4 \mathrm{mg} /$ $\mathrm{ml}$ fatty acid free $\mathrm{BSA}$, and $\mathrm{pH}=7.2$ ] supplemented with
$25 \mu \mathrm{g} / \mathrm{ml}$ digitonin. Thirty minutes after permeabilization and equilibration, Seahorse measurements (oxygen consumption rate, OCR) were initiated. Complex-specific substrates were used to drive specific respiration, while inhibitors were used to block the electron influx into the ETC from earlier complexes [cI: substrate was $5 \mathrm{mM} \mathrm{Pyr}, 2 \mathrm{mM}$ Gln, and $2.5 \mathrm{mM}$ Mal, inhibitor was $0.5 \mu \mathrm{M}$ rotenone; cII: substrate was $10 \mathrm{mM}$ succinate, inhibitor was $5 \mathrm{mM}$ malonate; cIII: substrate was $250 \mu \mathrm{M}$ duroquinol (TCI chemicals Germany, Eschborn, GER); inhibitor was $0.5 \mu \mathrm{M}$ antimycin A; cIV: $125 \mu \mathrm{M}$ TMPD $+2 \mathrm{mM}$ ascorbic acid, no specific inhibitor was used]. To reduce data variability, internal normalization of the OCR of each well was done relative to its value after equilibration.

\section{Generation and processing of LUHMES Temp0-Seq data}

Cells were cultured and treated as described above for the NeuriTox assay. On d3, after $24 \mathrm{~h}$ treatment, culture medium was replaced by $33 \mu \mathrm{l} /$ well $1 \times$ Biospyder lysis buffer. After $15 \mathrm{~min}$ at room temperature, plates were sealed and frozen at $-80{ }^{\circ} \mathrm{C}$ to complete lysis. Samples were analyzed at Bioclavis (Glasgow) using the TempO-Seq technique and the EU-ToxRisk v2.0 gene probe panel covering ca. 3000 genes (Yeakley et al. 2017). All genes are listed in the supplementary excel file (containing also all gene regulations). Briefly, a $50 \mathrm{bp}$ fragment of the target gene was amplified. The amplification step also introduced sample-specific barcodes. This allowed pooling of all samples and standard next-generation sequencing of the ensemble. Afterward, adapters were used to allocate the sequenced fragments to the correct samples. Finally, the alignment of all sequenced fragments (FASTQ files) for each sample to the collection of reference $50 \mathrm{bp}$ oligonucleotides was performed for the quantification of reads per gene, also known as the read count values. In a pre-filtering step, samples with a total count $<0.2$ million and genes with an average count $<1.5$ were removed. The effect of normalization was checked by boxplots and distribution plots (not shown), and no outlier samples were identified.

To correct for both read depth and RNA composition, the DESeq2's median of ratios normalization was applied. The analysis of differentially expressed genes (DEG) of each treatment against the control group was done by the Wald test implemented in DESeq2/R (Love et al. 2014), including an FDR correction for $\mathrm{p}$-adjusted $\leq 0.05$. To retrieve the effective concentration that caused $10 \%$ DEGs $\left(\mathrm{EC}_{10} \mathrm{DEG}\right)$, the total (upregulated + downregulated) number of DEGs per treatment condition was analyzed. A curve was fit through these concentration-response data to obtain $\mathrm{EC}_{10} \mathrm{DEG}$. For comparability, all DEG data were normalized to a positive control. We used $13 \mu \mathrm{M}$ deguelin (i.e., the $\mathrm{EC}_{10} \mathrm{~V}$ of 
deguelin) as positive control, and it triggered 325 DEGs. This response was set as $100 \%$ and all other DEGs' numbers were expressed relative to it; the response was limited to be no higher than $100 \%$, i.e., DEG numbers between 0 and 325 resulted in $0-100 \%$ response, and DEG numbers $>325$ were all set to full response $(=100 \%)$. The $\mathrm{EC}_{10} \mathrm{DEG}$ was calculated using an established online open access BMC calculator (BMCeasy) (Krebs et al. 2020).

\section{Curve fitting, data mining, and statistics}

If not mentioned otherwise, at least three independent experiments ( $=$ biological replicates, run from different cell batches) were performed. Data of treated samples were expressed relative to DMSO solvent controls, and they are reported as means \pm SEM. To calculate curve fits, a 4-parameter Hill model was used and the upper and lower asymptotes fixed to 100 and $0 \%$. Effective concentrations (EC) were determined by solving the Hill equation for $x \%$, e.g., $10 \%$ (for $x=10$ ) reduction of viability for the $\mathrm{EC}_{10} \mathrm{~V}$. Analysis of statistical differences was specified at individual methods sections (e.g., gene expression data) or figure legends (e.g., Figs. 1 and 5). For concentration-response data that were meant to give general overviews of effects and of the ranges of effect sizes, statistics were not performed for individual data points. This has several reasons. The two most import ones are that (i) in most cases, not the data points as such, but a summary measure of the curve, e.g., $\mathrm{BMC}_{10}$, was the main research result, and second (ii) for the multiple comparisons within and across many dimensions, most standard statistical approaches would yield problematic results or suggest an inappropriate exactness, given that data are interdependent to a certain degree, and that low $n$-numbers do not allow a solid basis for simple key assumptions (like normal distribution, etc.) when so many (hundreds of) comparisons are to be performed.

\section{Results and discussion}

\section{Assessment of key event activation along AOP\#03 and potential extensions of it}

The adverse outcome pathway (AOP) \#3 was used to guide the experiments performed in this study on inhibitors of mitochondrial respiratory chain (MRC) complexes I, II, and III (cI, cII, cIII). AOP:3 describes the binding (MIE) and inhibition (KE1) of a substance to cI, which subsequently leads to mitochondrial dysfunction (KE2), impaired proteostasis (KE3), nigrostriatal dopaminergic degeneration (KE4), and neuroinflammation (KE5). This may culminate in parkinsonian motor symptoms (AO) (Fig. 1) (Terron et al. 2018). As cII and cIII inhibitors are also expected to impair mitochondrial function, we investigated whether an extended AOP:3, starting at cII or cIII, could be substantiated with data indicating a link between cII/cIII inhibition and dopaminergic neurodegeneration, or whether cI inhibition is a special situation that is not recapitulated by other MRC inhibitors. To assess this, KE and biomarker assays were utilized to evaluate the activation of events downstream of the AO.

\section{Application of the NeuriTox test as KE4 assay to identify dopaminergic neurotoxicants (AO).}

To directly assess which of the cI-cIII inhibitors might be specific neurotoxicants causing dopaminergic neurodegeneration, the LUHMES-based NeuriTox assay was used as in vitro proxy (of in vivo degeneration and motor dysfunction). The test relies on the simultaneous assessment of neurite outgrowth and general cell viability (Fig. 2a) (Krug et al. 2013a; Stiegler et al. 2011). A strong heterogeneity regarding the compounds' potency and specificity (i.e., neurite damage without decrease in viability) was observed (Fig. 2b). Only rotenone and deguelin were active in the sub- $\mu \mathrm{M}$ range, and only rotenone and deguelin were specifically neurotoxic [i.e., $\mathrm{EC}_{25}(\mathrm{~V}) / \mathrm{EC}_{25}(\mathrm{NA})>4$ ]. For some compounds, the viability did not decrease sufficiently to allow calculation of the $\mathrm{EC}_{25}(\mathrm{~V}) / \mathrm{EC}_{25}(\mathrm{NA})$ ratio. They might also be specifically neurotoxic, but at higher concentrations. For many substances, especially cII and cIII inhibitors, no neurite effects $>25 \%$ were detected (definitely no specific neurotoxicity in the tested concentration range).

\section{Assessment of neurite degeneration in SH-SY5Y cells after either 24 or $120 \mathrm{~h}$ exposure}

As secondary, independent confirmation of the NeuriTox results, neurite degeneration was observed in two SH-SY5Ybased assays, after either $24 \mathrm{~h}$ or $120 \mathrm{~h}$ treatment (Fig. 3a). Viability was not affected for any of the compounds after $24 \mathrm{~h}$, at concentrations up to $10 \mu \mathrm{M}$ (not shown). Even after $120 \mathrm{~h}$ exposure, only a few compounds (rotenone, deguelin, fenpyroximate, antimycin A, and cyazofamid) caused a reduction in viability by $>25 \%$ and a degeneration of neurites after exposure with up to $10 \mu \mathrm{M}$ inhibitor (Fig. 3b). Three out of six cI inhibitors and two of five cIII inhibitors caused neurite effects $>25 \%$. In summary, the heterogeneous results from the NeuriTox test were largely recapitulated in SH-SY5Y cells.

Similar to the NeuriTox test, rotenone and antimycin A caused a specific neurite degeneration $>25 \%$ after $24 \mathrm{~h}$, without affecting viability. Cyazofamid also induced $>25 \%$ neurite degeneration without any signs of cytotoxicity in the SH-SY5Y cells, but no effects were observed after $24 \mathrm{~h}$ exposure with up to $10 \mu \mathrm{M}$ deguelin. Effects on neurite 


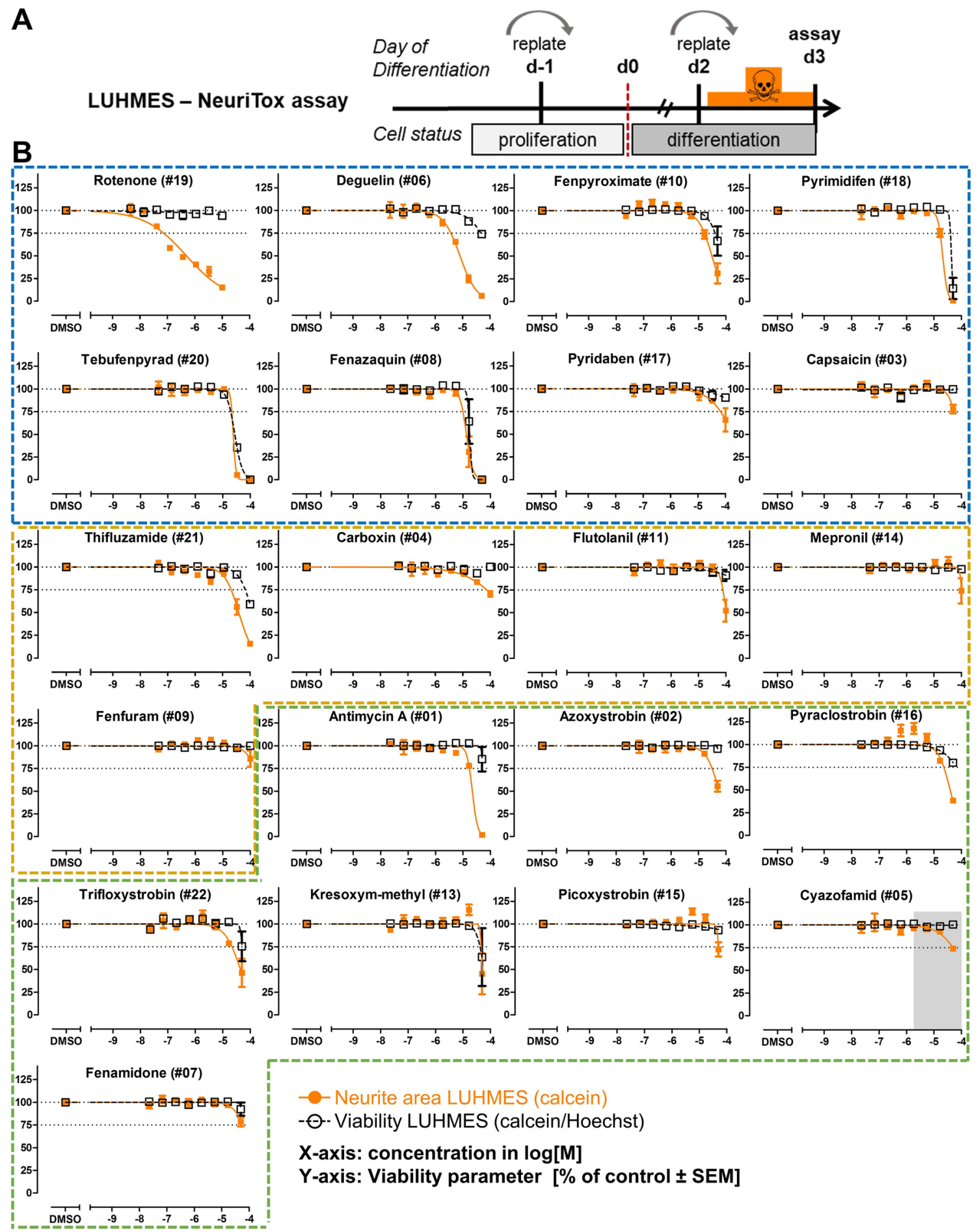

Fig. 2 Application of the NeuriTox test as KE4 assay to identify dopaminergic neurotoxicants (AO). a LUHMES cells were differentiated for $48 \mathrm{~h}$, and treated for $24 \mathrm{~h}$ after replating during their differentiation phase. Neurite outgrowth (NA, orange) and viability (V, black) were assessed on day $3(\mathrm{~d} 3)$ of differentiation by automated high-content imaging with calcein/H-33342 staining. b Graphs for individual compounds were ordered according to the described mode of action of the test compounds (cI, II, III inhibitors in blue, yellow, and green boxes) and their potency within their group. Gray area: compound was insoluble in that concentration range. Data are means \pm SEM from three independent experiments. The NeuriTox assay has an established prediction model, in which reductions of the neurite area by $\geq 25 \%$ are considered as (positive) hit (Delp et al. 2018a, b). Therefore, significance was not tested for individual data points, but the threshold is indicated by dotted lines (color figure online) 
A

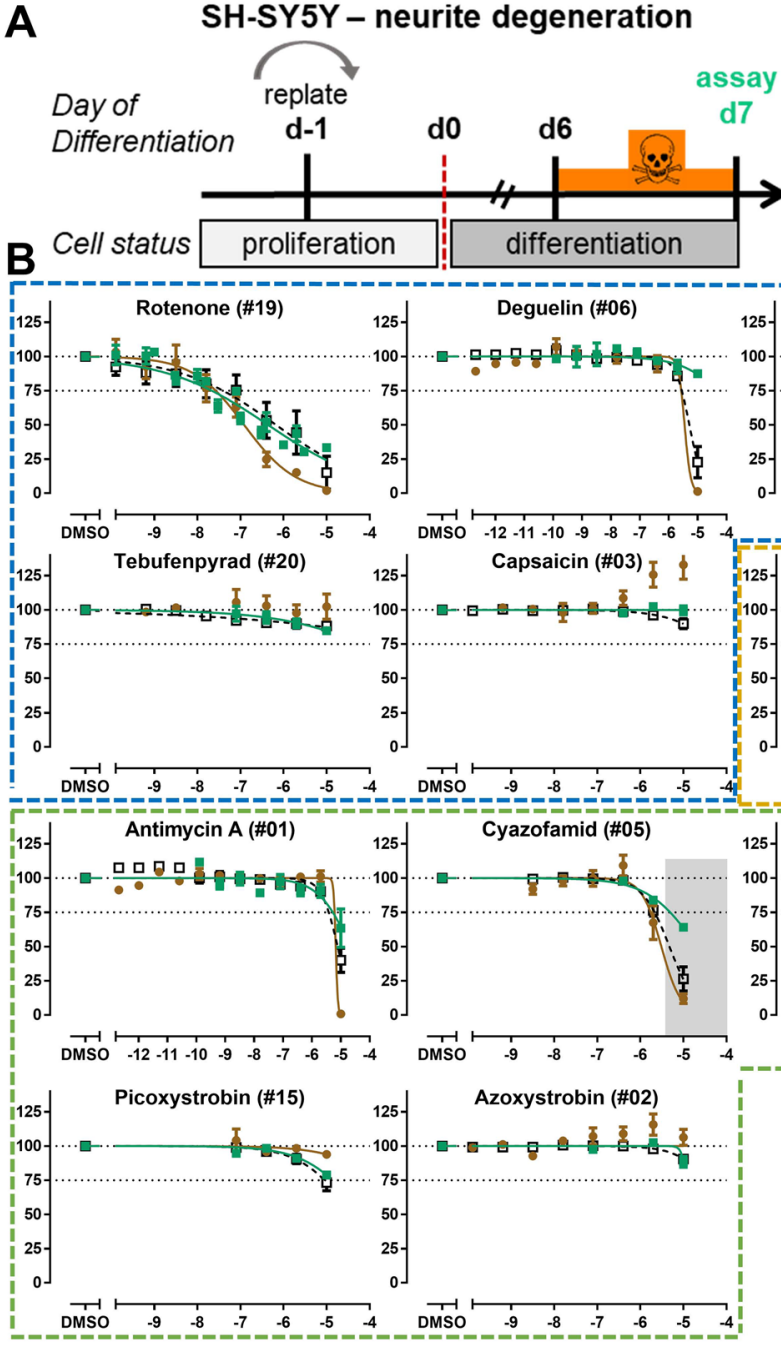

SH-SY5Y - Repeated dosing

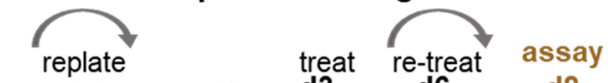

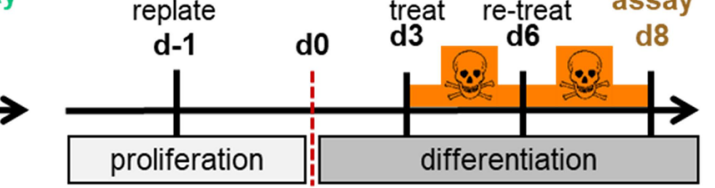
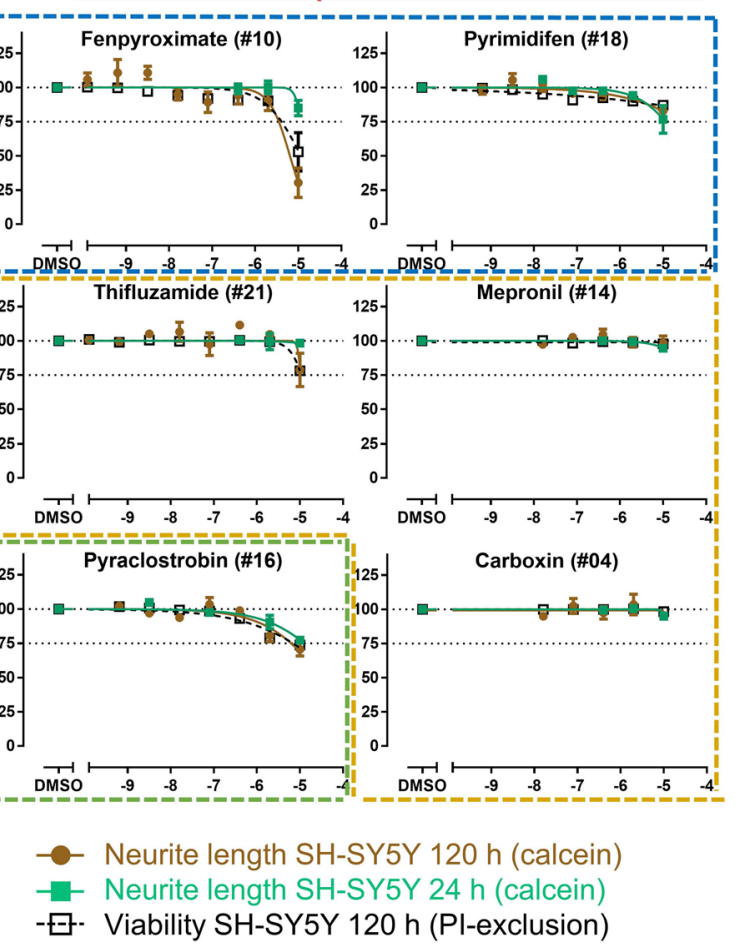

$\mathrm{X}$-axis: concentration in $\log [\mathrm{M}]$

Y-axis: Viability parameter [\% of control \pm SEM]

Fig. 3 Assessment of neurite degeneration in SH-SY5Y cells after either 24 or $120 \mathrm{~h}$ exposure. a For the short exposure scenario (left), SH-SY5Y cells were differentiated for 6 days and treated once for $24 \mathrm{~h}$ (green). For the long-exposure scenario (right), the cells were differentiated for 3 days, subsequently treated 3 days, and retreated for another 2 days (brown). Neurite length and viability (black) were determined on day 7 ( $24 \mathrm{~h}$ exposure) or day 8 (120 h exposure), using high-content imaging and calcein/propidium iodide staining. b Concentration-response graphs for cI (blue), cII (yellow), and cIII (green) inhibitors, ordered according to the compounds' potency within their MoA group. Note: only the $120 \mathrm{~h}$ viability data were plotted, since a $24 \mathrm{~h}$ exposure did not affect viability under any condition tested. Data are means \pm SEM from three independent experiments (color figure online)

$120 \mathrm{~h}$ exposures (Suppl. Fig. 3b), but the $\mathrm{EC}_{25}$ values were in most cases slightly lower for the $120 \mathrm{~h}$ data set (Suppl. Fig. 3c). For pyrimidifen, we observed a 9.8 -fold increase in sensitivity. For deguelin, thifluzamide, fenpyroximate, pyraclostrobin, and cyazofamid, the increase was five-toeightfold. Neurite degeneration for all these compounds was also enhanced to a similar degree in SH-SY5Y cells after prolonged exposure (Fig. 3). However, longer exposures also had the disadvantage that viability decreased stronger after $120 \mathrm{~h}$ than after $24 \mathrm{~h}$, triggering the problem that discrimination between specific neurotoxicants and general toxicants becomes difficult. 


\section{Assessment of specific neurotoxicity}

We also pursued another concept to define specific neurotoxicity: cytotoxicity data from LUHMES and SH-SY5Y were compared to data from an unrelated, non-neuronal cell line, i.e., U2OS carcinoma cells (Fig. 4). The neurite area of LUHMES cells (or neurite length in SH-SY-5Y cells) was on average more sensitive to MRC inhibitors than U2OS viability. However, the observed effects were heterogeneous within cI inhibitors, with rotenone showing a $>100$-fold offset, deguelin a $>$ tenfold offset and other compounds rather with one-to-fivefold offsets. For cIII inhibitors, also large difference were observed (antimycin A being a potentially strong neurite-specific toxicant). It was also of interest to correlate effects on intracellular ATP levels with viability effects. Most compounds decreased ATP at similar concentrations as they affected the neurites. A notable exception was again rotenone. This extensive comparison showed that compounds with apparently similar modes of action (MRC inhibition) may show distinct toxicological effects. Both neuronal cell models showed a high concordance in the prediction of potentially specific neurotoxicity, whatever approach was applied. Notably, all data suggested that cII inhibitors have a low neurotoxic potency.

\section{Assessment of proteostasis endpoints for KE3}

After this broad coverage of KE4/AO by various in vitro assays, we worked our way backwards along the AOP. KE3 (disturbed proteostasis) was examined next. Proteostasis is a complex process, and we chose an assay that includes several cellular functions (comprising synthesis and sorting of proteins and lipids). In simple terms, the metabolic glycoengineering (MGE) assay measures the efficiency of cell surface glycolipid and glycoprotein production from a sugar precursor (Fig. 5a). For this purpose, a labeled sugar (precursor) was fed to LUHMES cells, and the display of this sugar (= sialic acid) on the cell surface in the form of glycolipids and glycoproteins was quantified by a fluorescent staining and imaging method (Kranaster et al. 2020). As exemplified for antimycin A, a strong decrease in the neurite MGE signal (glycolipids/glycoproteins on the surface of neurites) was observed in the absence of cell death. The toxicant even led to a reduction of the MGE signal on

\begin{tabular}{|c|c|c|c|c|c|c|c|c|c|c|}
\hline \multirow{3}{*}{ ID\# } & \multirow{3}{*}{ Compound } & \multirow{3}{*}{ Target } & \multirow{3}{*}{$\begin{array}{c}\text { Cytotox } \\
\text { EC25 } \\
\text { U2OS }\end{array}$} & \multicolumn{3}{|c|}{ LUHMES 24 h EC25 } & \multicolumn{2}{|c|}{ Neurite-specific effect } & \multicolumn{2}{|c|}{ Neuronal-specific effect } \\
\hline & & & & ATP & An & 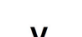 & V & $\underline{\text { ATP }}$ & U2OS & U2OS \\
\hline & & & & AIT & INA & $\mathbf{v}$ & NA & NA & LUHMES NA & SH-SY5Y NA \\
\hline 03 & Capsaicin & $\mathrm{Cl}$ & 4.2 & $<4.3$ & $<4.3$ & $<4.3$ & 1.0 & n.a. & n.a. & n.t. \\
\hline 06 & Deguelin & $\mathrm{cl}$ & $<4.3$ & 5.0 & 5.4 & 4.3 & 12.3 & 2.6 & $>13.5$ & $>18.2$ \\
\hline 08 & Fenazaquin & $\mathrm{cl}$ & $<4$ & 5.0 & 5.0 & 4.8 & 1.6 & 1.0 & n.t. & n.t. \\
\hline 10 & Fenpyroximate & $\mathrm{cl}$ & $<4.3$ & 4.9 & 4.8 & 4.4 & 2.4 & 0.9 & $>3$ & $>14.1$ \\
\hline 17 & Pyridaben & $\mathrm{cl}$ & $<4$ & 4.1 & 4.2 & $<4$ & $>1.5$ & 1.3 & $>1.5$ & n.t. \\
\hline 18 & Pyrimidifen & $\mathrm{cl}$ & 4 & 4.7 & 4.8 & 4.4 & 2.3 & 1.1 & 5.9 & n.a. \\
\hline 19 & Rotenone & $\mathrm{cl}$ & 4.5 & 5.3 & 7.1 & $<5$ & $>130$ & 76 & 430 & 1200 \\
\hline 20 & Tebufenpyrad & $\mathrm{cl}$ & $<4$ & 4.9 & 4.7 & 4.7 & 0.9 & 0.6 & $>4.7$ & n.a. \\
\hline 04 & Carboxin & cll & $<4$ & $<4$ & 4.1 & $<4$ & $>1.4$ & $>1.4$ & $>1.4$ & n.a. \\
\hline 09 & Fenfuram & cll & $<4$ & $<4$ & $<4$ & $<4$ & 1.0 & n.a. & n.a. & n.t. \\
\hline 11 & Flutolanil & cll & $<4$ & 4.1 & 4.1 & $<4$ & $>1.3$ & 0.9 & $>1.3$ & n.t. \\
\hline 14 & Mepronil & cll & $<4$ & $<4$ & 4.0 & $<4$ & $>1$ & $>1$ & n.a. & n.a. \\
\hline 21 & Thifluzamide & cll & 4.7 & 4.7 & 4.7 & 4.2 & 3.2 & 1.0 & 1.0 & n.a. \\
\hline 01 & Antimycin A & cIII & 4 & 4.6 & 4.8 & $<4.3$ & $>2.9$ & 1.4 & 5.8 & 16.6 \\
\hline 02 & Azoxystrobin & clll & $<4$ & $<4.3$ & 4.5 & $<4.3$ & $>1.6$ & $>1.6$ & $>3.2$ & n.a. \\
\hline 05 & Cyazofamid & clll & 4 & $<4.3$ & 4.3\# & $<4.3 \#$ & $>1$ & $>1$ & 2.0 & 57.5 \\
\hline 07 & Fenamidone & clll & $<4$ & $<4.3$ & $<4.3$ & $<4.3$ & 1.0 & n.a. & n.a. & n.t. \\
\hline 13 & Kresoxim-methyl & clll & $<4$ & 4.5 & 4.3 & 4.4 & 0.9 & 0.6 & $>2.2$ & n.t. \\
\hline 15 & Picoxystrobin & clll & $<4$ & 4.4 & 4.3 & $<4.3$ & $>1$ & 0.8 & n.a. & n.a. \\
\hline 16 & Pyraclostrobin & cIll & $<4$ & 4.9 & 4.6 & $<4.3$ & $>1$ & 0.6 & $>4.4$ & $>15.8$ \\
\hline 22 & Trifloxistrobin & clll & 4.3 & 4.4 & 4.7 & 4.3 & 2.3 & 1.8 & 2.3 & n.t. \\
\hline
\end{tabular}

Fig. 4 Synoptic overview of measures of specific neurotoxicity. Compounds are grouped according to their MoA. Columns 4-7 of the table indicate the potency of the test compounds for different test endpoints, are given in $-\log [\mathrm{M}]$, and refer to the EC25 values. Concentrations were coded from intense blue (=highly active, low concentration) to light blue (= less active, high concentration); when the highest tested concentration did not result in $25 \%$ effect, the cell was colored gray. Columns $8-11$ give potency ratios, calculated using potency data in their non-logarithmic form. Ratios were colored according to the established prediction model of the NeuriTox test, i.e., red if $>4$ (=specific neurotoxicity), gray if $<4$, i.e., unspecific, and orange if the ratio could not be fully calculated due to a lack of effect in the assessed concentrations, but was $\geq 2$. Unspecific cytotoxicity was assessed using U2OS cells (osteosarcoma; treated for $24 \mathrm{~h}$, cytotoxicity was measured by luminescence of constitutively expressed luciferase). The LUHMES $24 \mathrm{~h}$ endpoints were generated following the NeuriTox exposure scheme as in Fig. 2; the SH-SY5Y endpoint was determined by treating the cells for $120 \mathrm{~h}$ (data taken from Fig. 3). cI-III: electron transport chain complex I, II, or III; V: viability; NA: neurite area, n.t.: not tested; n.a.: ratio could not be calculated as compound did not trigger toxicity; \#: cyazofamid was found to precipitate in the active concentration range; thus, it was considered to be inactive (color figure online) 
A

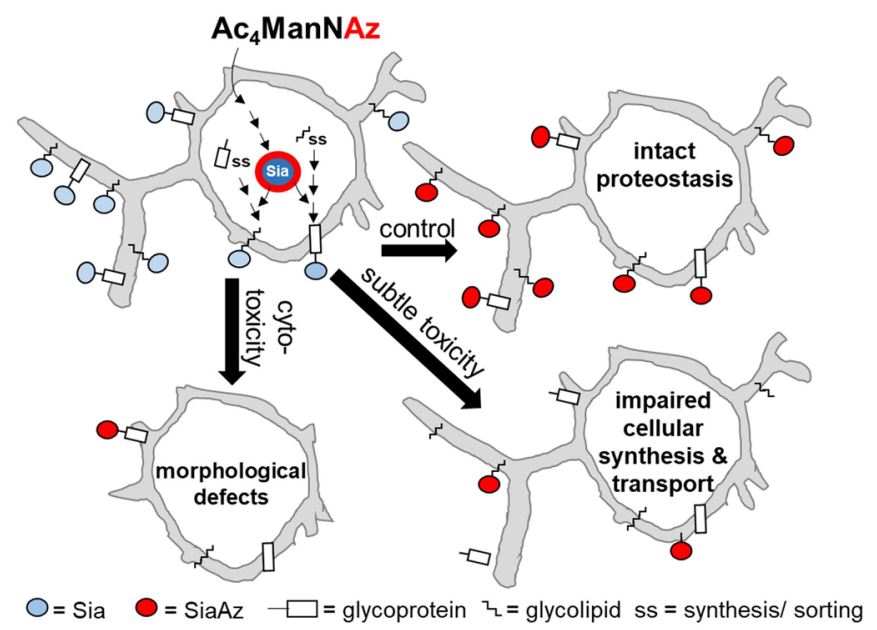

C
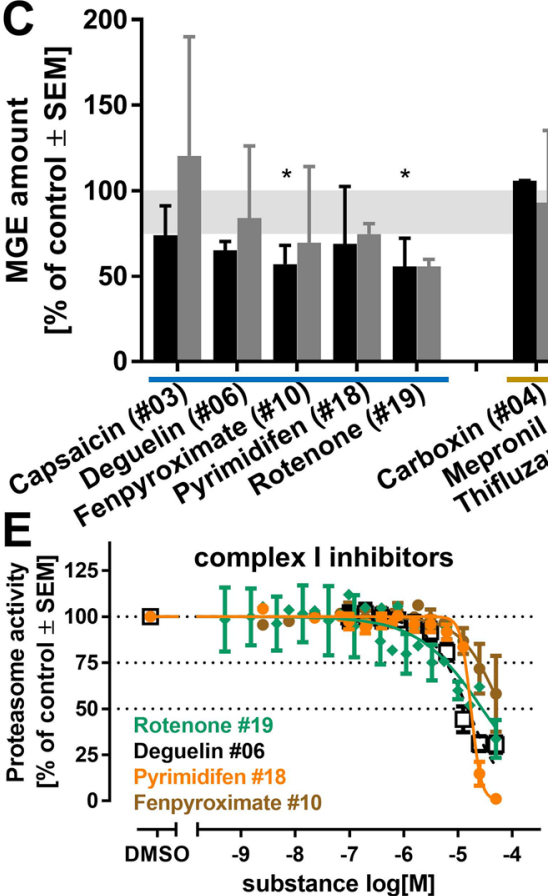

substance $\log [\mathrm{M}]$
B

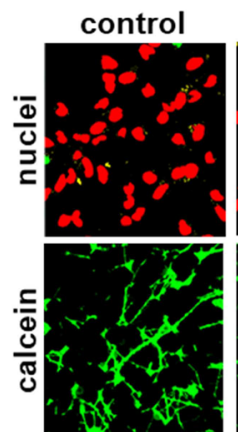

Anti A
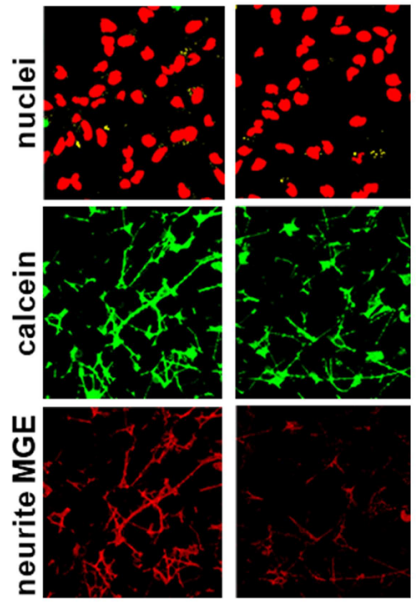

No fluo-

rescence

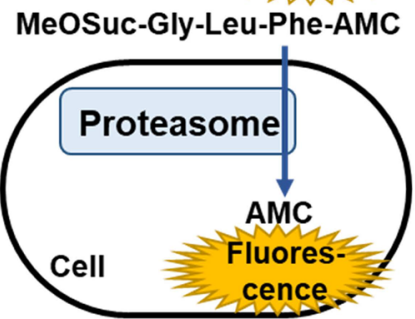

Fig. 5 Assessment of proteostasis endpoints. a Proteostasis consists of several processes, including synthesis, sorting, and glycosylation of lipids and proteins. These are assessed by the NeuroGlycoTest, which is based on metabolic glycoengineering (MGE), i.e., feeding of modified mannosamine sugars (peracetylated $\mathrm{N}$-azidoacetylmannosamine, Ac4ManNAz) to cells. These are used instead of their natural analogs (N-acetylmannosamine, ManNAc) by glycosylation enzymes. These sugars become covalently linked to the proteins and lipids (as azide-modified sialic acid: SiaAz/Sia), and are then transported to the cell membrane. If toxic compounds interfere with any step of this proteostatic process, a reduced cell surface glycosylation can be detected (modified from (Kranaster et al. 2020)). b Example pictures of LUHMES cells treated for $6 \mathrm{~h}$ with $50 \mu \mathrm{M}$ antimycin A (Anti A) or vehicle control. The first row shows nuclei stained with H-33342 as control for cell number and viability. The second row shows neurites stained with calcein (cell bodies were removed by image analysis algorithm). The third row displays the labeled sialic acids (as stained by MGE and a subsequent color reaction) on neurites. Pictures have a width of $166 \mu \mathrm{m}$. c A subset of 14 test compounds was investigated at their highest non-toxic concentration (concentrations given in Suppl. Figure 4) for effects on the sialic acid content on the surface of neurites (neurite MGE). As second endpoint, cells were lysed and the total amount of MGE labeled sialoproteins was determined by Western blot (sialoprotein MGE). Both endpoints were normalized to DMSO controls of two independent experiments. Error bards indicate the data range. To identify significant changes, a one-way ANOVA followed by Fisher's LSD test was performed, *: $p<0.05$. d To investigate the proteasomal activity as alternative indicator of proteostasis, d2 LUHMES cells were incubated with toxicants for $22 \mathrm{~h}$. Subsequently, cell culture medium was replaced by assay buffer containing a cell-permeable proteasomal substrate. The coumarin fluorescence (AMC) generated by the proteasomal activity was quantified as described earlier (Gutbier et al. 2018b). e The proteasome activity was determined for selected cI-III inhibitors. Data are means \pm SEM from three to four independent experiments 
neurites that were still intact (Fig. 5b). We chose the highest non-cytotoxic concentration (determined in the NeuriTox test) to test the core subset of inhibitors. In addition to the fluorescent endpoint, we also used Western blotting to quantify the amount of glycosylated proteins (= sialoproteins) (Suppl. Fig. 4c). Both endpoints were affected in a similar way by the test compounds, but the effects on the Western endpoint were less pronounced than in the fluorescent imaging assay (Fig. 4c, Suppl. Fig. 8b). According to this assay (termed here NeuroGlycoTest), cII inhibitors did not cause significant disturbances of proteostasis; some cI and cIII inhibitors showed clear effects. At the test concentration used, none of the inhibitors reduced cell viability, and only antimycin reduced the neurite area by more than $25 \%$ (Suppl. Fig. 4a). This suggests that effects in the NeuroGlycoTest were not only a passive consequence of neurite loss. In summary, these data suggest that changes in proteostasis are consistent with changes in the KE4/AO. However, the assay chosen here has a low throughput, and will require further work and optimization to be incorporated in a testing battery. It will also need to be compared to other potential proteostasis assays. At present, there is no consensus how to quantify this KE, and exploratory approaches as the one presented here are necessary. We contributed to this exploration by choosing two alternative assays within this study.

To assess a second endpoint of proteostasis, proteasomal function (enzymatic activity of the proteasome) was investigated in the same exposure scenario as for the NeuriTox test. To achieve this, we exposed cells to a cell-permeable substrate that becomes fluorescent upon cleavage by the proteasome. Quantification of the fluorescence can then be taken as measure of cellular proteasome activity (Fig. 5d). We observed indeed a concentration-dependent decrease in proteasomal function for all examined substances. However, this occurred only at concentrations that affected also the overall cell viability. The only exception was rotenone, which reduced proteasome function at non-cytotoxic concentrations (Fig. 5e). We conclude on this assay that it lacks sensitivity to measure effects on proteostasis that occur in still viable cells, and this approach was therefore not further pursued.

\section{Investigation of transcriptomic changes as biomarker for intermediate key events}

An entirely different approach to define altered proteostasis makes use of high content Omics technologies (transcriptomics or proteomics) that would identify multiple changes in an unbiased way. We used here changes of the transcriptome, as biomarker of cellular changes related (indirectly) to changes of protein functions and expression levels. The TempOSeq high-throughput technology was applied here to allow multiple sampling at multiple concentrations. Samples were obtained from cells exposed for $24 \mathrm{~h}$ to five concentrations of $14 \mathrm{MRC}$ inhibitors. All test compound concentrations were anchored to the respective $\mathrm{EC}_{10} \mathrm{~V}$ values from the NeuriTox assay, so that for each compound, one data set was obtained for the highest non-cytotoxic concentration. A principle component analysis showed that all compounds exhibited a response different from the negative control (0.1\% DMSO) at their respective $\mathrm{EC}_{10} \mathrm{~V}$. There was no obvious clustering of compounds according to the mode of action (e.g., cIII inhibitors were widely spread) (Fig. 6a).

To reduce the complexity of the analysis, and to allow still some information on concentration-response behavior and on similarity of responses between compounds, we took the following approach: (i) a gene set was identified that qualified as typical of neuronal cI inhibition; (ii) we checked for a selected compound (deguelin) the concentration dependency of gene regulation for this set; (iii) we checked for all compounds at a given concentration $\left(\mathrm{EC}_{10} \mathrm{~V}\right)$ the congruence of dysregulation (Fig. 6b, c).

To select a typical cI gene set, we chose deguelin as gold standard. This compound showed strong responses in all KE assays, is a well-characterized, typical cI inhibitor (Delp et al. 2019; van der Stel et al. 2020) and behaves less extreme than rotenone. We selected all 13 genes that were differentially regulated by deguelin at its $\mathrm{EC}_{10} \mathrm{~V}$ $(13 \mu \mathrm{M})$, and at the next lower concentration $(3.25 \mu \mathrm{M})$, to make sure that no unspecific indicators of cell death were included. This gene set included NQO1 (typical oxidative stress response) as usual suspect. It also comprised several genes related to microtubules (motor proteins and centrosome/spindle-related proteins), which suggests that a general disturbance of proteostasis occurred (Supp Fig. 5). Concentration-response analysis showed that 11 out of 13 of these genes were not significantly regulated up to $0.8 \mu \mathrm{M}$ deguelin, but clearly upregulated at $3.25 \mu \mathrm{M}$. Above this concentration, the extent of regulation more or less reached a plateau, suggesting that these genes are not related to cell death (which was triggered in our system at the highest test concentration of $25 \mu \mathrm{M}$ (Fig. 6d).

In a second step, we checked whether these genes were also affected by the other MRC inhibitors. All compounds active in the NeuriTox assay (all compounds, but capsaicin, mepronil, and cyazofamid) showed a dysregulation pattern that was very similar to deguelin. These data indicate that mitochondrial inhibitors with different modes of action show some similarities in their proteostasis response (Fig. 6b, c). Recently, indeed, a link has been found that links mitochondrial stress to the cytosolic stress response (Fessler et al. 2020). This pathway involves activation of the transcription factor $\mathrm{CHOP}$ and, therefore, may explain the gene regulation response triggered by mitochondrial inhibitors. Another way to relay 
A

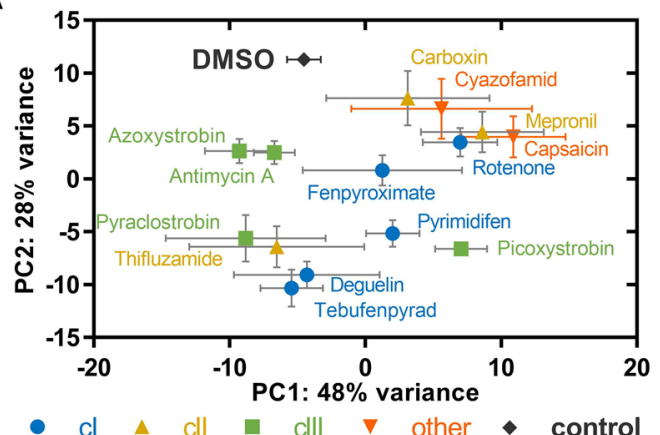

B

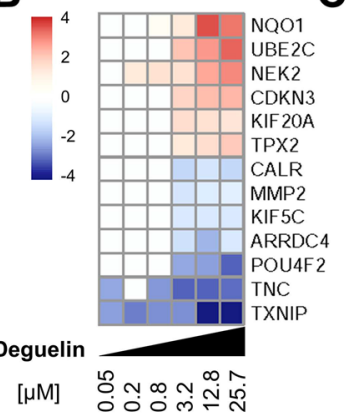

C

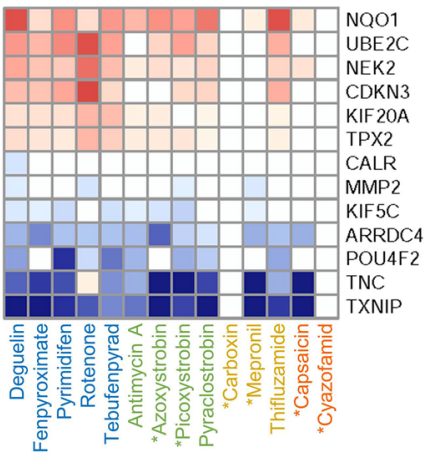

D
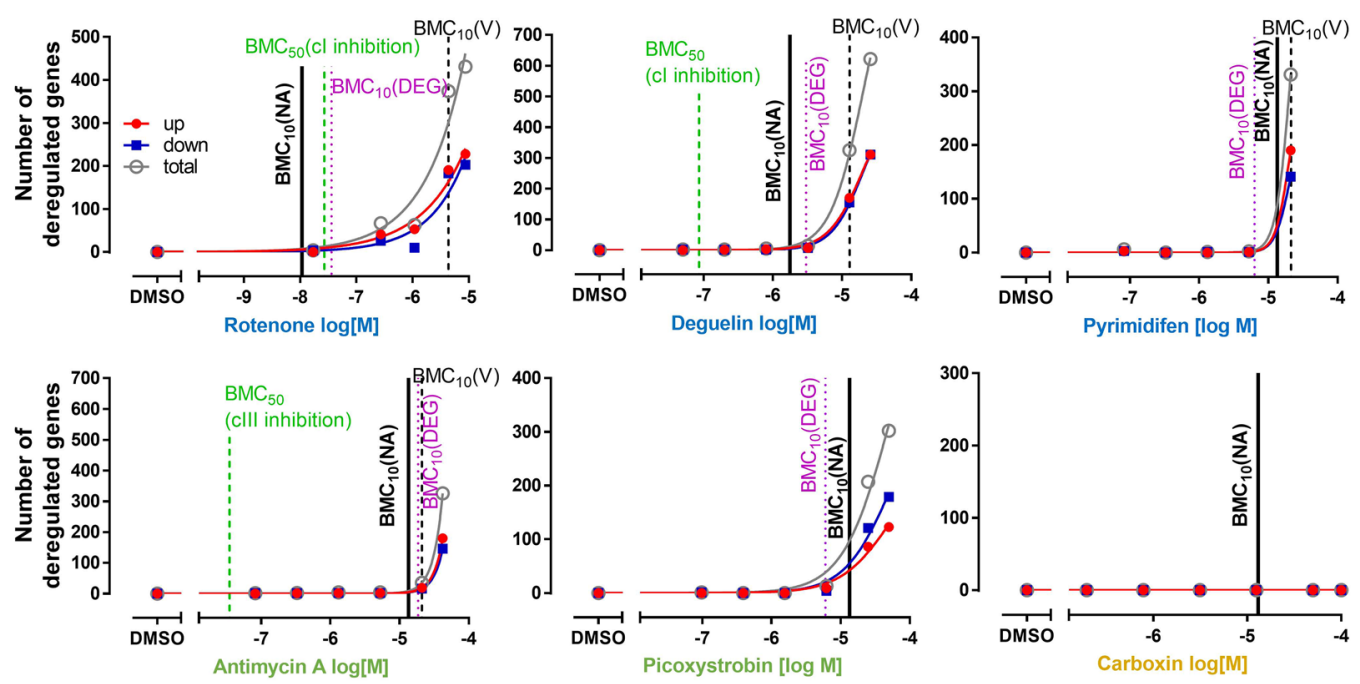

Fig. 6 Investigation of altered mRNA transcripts as biomarker for mitochondrial respiratory chain impairment. a LUHMES cells were differentiated for $48 \mathrm{~h}$ and subsequently treated for $24 \mathrm{~h}$. Analysis of the transcriptome (mRNA expression) was performed using Biospyder's TempO-Seq technique. Test concentrations were the highest non-cytotoxic levels according to the NeuriTox assay. For noncytotoxic compounds within the testing range, the highest possible concentration, i.e., 100 or $50 \mu \mathrm{M}$, was chosen (marked *). To visualize the overall data structure, a principal component (PC) analysis was performed. The 100 most variable genes were used to calculate the coordinates of $\mathrm{PC} 1$ and $\mathrm{PC} 2$, replicate values were plotted as mean \pm SEM from 3 independent differentiations. Color-coding was applied based on the compounds' MoA (respiratory chain complex inhibition), the PCA axes dimensioning was adjusted according to the variance explained by the individual PCs. b Genes regulated by deguelin as typical complex I inhibitor with strong transcriptional response were identified for $\mathrm{EC}_{10} \mathrm{~V}(13 \mu \mathrm{M})$ and for a $4 \times$ lower concentration $(3.25 \mu \mathrm{M})$. The 13 overlap genes were considered to be regulated by definitely non-cytotoxic concentrations. They were used for expression analysis over the entire concentration range (26-0.05 $\mu \mathrm{M})$. Upregulation by deguelin was color-coded red, downregulation in blue, using a diverging scale of $\log 2$ fold change values. Regulations that had an FDR-corrected $\mathrm{p}$ value $>0.1$ were colored white; data were from three independent differentiations; DEG were determined vs DMSO controls. c The regulation of the "deguelin-sensitive genes" identified in b) was investigated for all 14 compounds (tested at their $\mathrm{EC}_{10} \mathrm{~V}$ concentration, if this was not reached, the highest tested concentration was used. $\mathbf{b}+\mathbf{c}$ The mean fold change in expression relative to control from three independent differentiations was color-coded: blue indicates down-regulation, red indicates up-regulation, and white indicates that the regulation had an FDRadjusted $p$ value $>0.1$. Compound colors indicate their target (cI, cIII, cII, other). d Concentration-response analysis of significantly differentially expressed genes (DEG). As reference values, the $\mathrm{BMC}_{50}$ concentrations of the respective respiratory chain complex inhibition (assessed in LUHMES cells) as well as the $\mathrm{EC}_{10}$ of viability $\left[\mathrm{BMC}_{10}(\mathrm{~V})\right]$ and neurite outgrowth impairment $\left[\mathrm{BMC}_{10}(\mathrm{NA})\right]$ have been added (vertical dashed lines). DEG were defined by $>1.5$-fold regulation $(0.59$ on $\log 2$ scale $)$ and an FDR-corrected $p$ value $<0.05$ (data from three independent differentiations). The dotted pink line indicates the " $\mathrm{BMC}_{10}$ " of gene regulation $\left[\mathrm{BMC}_{10}(\mathrm{DEG})\right]$. To determine this value, the degree of gene expression homeostasis (DGH) was defined as $\mathrm{DGH}=100$-number of deregulated genes; with a lower limit of DGH set to 0 . The concentration-dependent DGH values were used as input for an algorithm to determine benchmark concentrations (Krebs et al. 2020) [http://invitrotox.uni-konstanz.de/ $\mathrm{BMC} /]$ and $\mathrm{BMC}_{10}$ values were retrieved (color figure online) 
such signals may involve reactive oxygen species produced by mitochondria and acting on cytosolic stress response systems (Krug et al. 2014).

Many more analyses would be possible, and we make all data available for this purpose (see suppl. Excel file). Our main intention here was to check the overall data structure and then to see whether a simple measure of the transcriptome response may be used as KE assay. We chose the overall number of differentially regulated genes (DEG) as potential endpoint, and used these data for curve fitting and determination of a benchmark concentration (BMC) of gene regulation [i.e., a concentration that may be regarded as threshold for gene regulation/ disturbed proteostasis, $\left.\mathrm{BMC}_{10}(\mathrm{DEG})\right]$. This concentration was designated here $\mathrm{BMC}_{10}(\mathrm{DEG})$, and it was compared to the $\mathrm{BMC}_{10}$ for viability, for neurite growth, and for MRC complex inhibition (Fig. 6d, Suppl. Fig. 6).

The general cell viability was always the least sensitive endpoint. The question of whether neurite data or transcriptomics data were more sensitive to indicate potential toxicity was particularly interesting. For deguelin, both endpoints were in the same range, but cI inhibition occurred at considerably lower concentrations. This means that the specific KE4/AO endpoint (neurite damage) correlated with transcriptome changes and disturbed proteostasis; and that a certain extent of MRC inhibition neither triggered gene regulation, nor neurotoxicity.

For rotenone, neurite damage was the most sensitive endpoint. It occurred at $<50 \%$ cI inhibition, and before genes were deregulated. This data set supports an outlier role for rotenone, possibly due to a second target, different from cI. The situation for antimycin A was similar to the one for deguelin. When looking at all other compounds, some heterogeneity was apparent, as for some the gene regulation and for others, the neurite response was the more sensitive endpoint. In general, these measures were very often within a less than threefold variation (Fig. 6d, Suppl. Fig. 6).

From these data, we conclude that high-throughput transcriptomics, used for the determination of the number of DEG, may be used as endpoint to assess potential neurotoxicity, and that it is a biomarker indicating disturbed proteostasis. The data clearly indicate that no-effect levels exist for gene regulation and that this endpoint is not necessarily over-sensitive. Data from more systems will be required to decide on the overall sensitivity and specificity of this endpoint, and readout optimizations may be obtained by selections of particular gene sets like stress response genes (Wink et al. 2018; Zgheib et al. 2018), differentiation-related genes (Dreser et al. 2020), or good collections of genes related to the specific KE or AO under investigation.

\section{Investigation of the mitochondrial membrane potential (MMP) and resazurin reduction impairment to assess KE2}

According to the AOP:3, the KE4/AO can not only be triggered by KE3 (disturbed proteostasis), but also (directly) by KE2 (mitochondrial dysfunction). In our approach of working backwards along the AOP, we used assays relevant to KE2. Measurements of the mitochondrial membrane potential (MMP) were used here as main approach, as the MMP is a well-established proxy of mitochondrial function. For this assay, we used SH-SY5Y cells, as the endpoint is well established for this test system (Feng et al. 2020; Gustafsson et al. 2004; Kim et al. 2017; Pakrashi et al. 2020). The cells were cultured and exposed for $24 \mathrm{~h}$ as for the neurite degeneration assay (see Fig. 3). General cell viability was assessed in parallel by the resazurin reduction test (Fig. 7a), and none of the MRC inhibitors was bluntly cytotoxic (resazurin reduction was always $>75 \%$ of control values). In this setting, the MMP was affected drastically by many compounds at non-cytotoxic concentrations. All confirmed cI and cIII inhibitors (excluding capsaicin) decreased the MMP by at least $60 \%$. The cII inhibitors showed less pronounced effects (none reached a 60\% inhibition, but carboxin reached at least $50 \%$ ). Thus, this assay proved to be a very sensitive endpoint (Fig. 7b).

To complement these data, we also used LUHMES cells to measure resazurin reduction (Suppl. Fig. 7a). This endpoint measure was not reduced by MRC inhibitors (at concentrations below those also affecting the neurites). In fact, the resazurin signal often was rather increased. This is a frequently observed artifact, most likely linked to changes of cellular metabolism, like the increase of the reducing agent NADH (Blacker and Duchen 2016) (Suppl. Fig.7b). As the MMP assay is not established for LUHMES cells, we explored whether intracellular ATP levels could be a sensitive indicator of mitochondrial dysfunction. However, a decrease was not observed at concentrations lower than those affecting neurite morphology (Suppl. Fig. 7b; synoptic overview in Fig. 4). In summary, the SH-SY5Y MMP assay proved to be most suitable to test mitochondrial dysfunction. We observed earlier that different cell types can give different MMP data and each test system requires a lot of method adaptations to yield robust results (van der Stel et al. 2020). The LUHMES assay did not work under conditions that were optimal for SH-SY5Y cells. An alternative mitochondrial function assay in LUHMES cells relies on the comparison of test results in glucose vs galactose medium. We found for some compounds (rotenone, deguelin, and antimycin) that ATP measurements in galactose medium may be an indicator of mitochondrial function (Delp et al. 2019). This assay was not used here, as the SH-SY5Y system already provided a suitable KE2 assay, and as the interpretation of 
A

SH-SY5Y - neurite degeneration exposure scheme Mitochondrial membrane potential (MMP) and resazurin reduction assay B
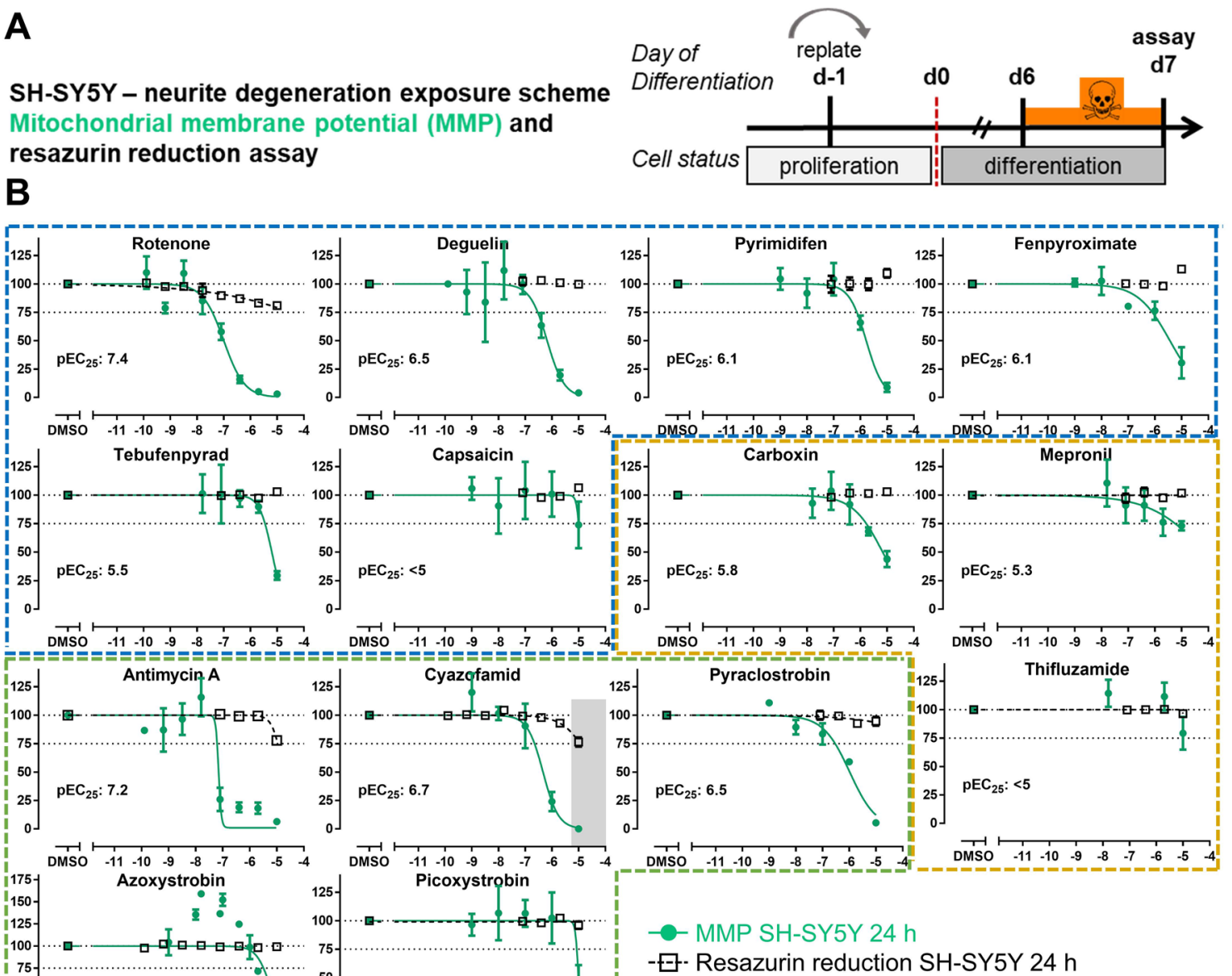

$X$-axis: concentration in log[M] Y-axis: Viability parameter [\% of control \pm SEM]

Fig. 7 Investigation of mitochondrial membrane potential (MMP) and resazurin reduction impairment to assess KE2. a SH-SY5Y cells were differentiated for 6 days and subsequently treated for $24 \mathrm{~h}$. Endpoints were determined using either rhodamine-123 for MMP (green) or resazurin reduction for overall viability (black). b Concentration-response graphs for the subset of cI (blue), cII (yellow), and cIII (green) inhibitors, ordered according to the compounds' potency within their MoA group. Data are means \pm SEM from three independent experiments. The numbers in the graphs indicate the $\mathrm{EC}_{25}$ for MMP (crossing point of MMP curve fit with dotted line at $75 \%$ ). These data are used for downstream data comparisons as KE2 output. $\mathrm{pEC}_{25}:-\log [\mathrm{M}]$ concentration where MMP was reduced by $25 \%$ (color figure online)

information on the MIE/KE1 (binding to MRC complexes and inhibition of their activity). LUHMES cells were tested at the highest non-cytotoxic concentration (determined from the NeuriTox assay, Fig. 2). Investigation of the total mitochondrial respiration of intact cells showed that all cI inhibitors (except capsaicin) had strong (>75\%) inhibitory effects (Fig. 8a). Capsaicin showed a weak response. For further confirmation, we investigated the biochemical activity of the compounds more directly in permeabilized cells. In this assay, electrons can be fed specifically into cI of the respiratory chain (Suppl. Figure 8a), and all cI inhibitors were confirmed to block cI to a high degree, with the only exception of capsaicin (no significant response at $50 \mu \mathrm{M}$ ) (Suppl. Fig. 8b, d). These 


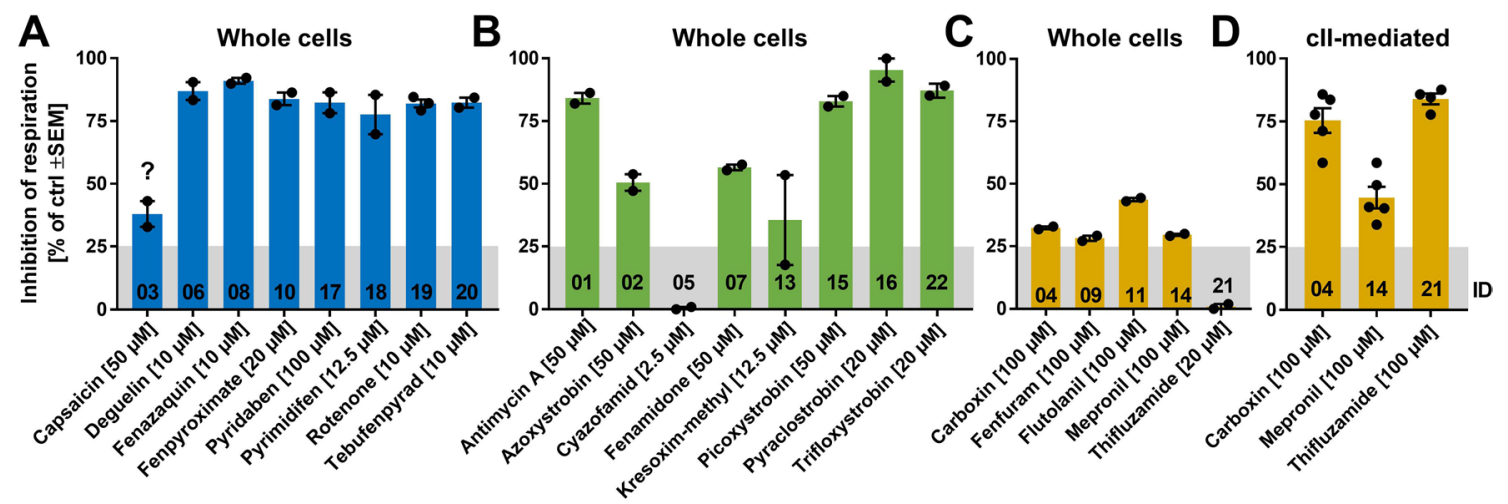

Fig. 8 Quantification of respiration of intact and permeabilized LUHMES cells. a-c As assay to assess MIE, KE1, and KE2, intact (whole cells) d3-differentiated LUHMES cells were acutely treated with the indicated inhibitors at their highest non-cytotoxic concentration and changes in mitochondrial oxygen consumption rate were quantified. Compounds are grouped and color-coded according to their MoA (inhibitors of cI, III, and II in blue, green, yellow). d Inhibition of cII activity by cII inhibitors was assessed using permeabi- lized LUHMES cells as depicted in Suppl. Figure 7. The assay specifically assesses cII activity. The numbers at the bottom of the bars indicate the compound ID. Bars represent means \pm SEM, and each point represents the result of an independent experiment. The gray area is the negative control noise band of the assay as defined in (Delp et al. 2019), i.e., inhibition within this range is regarded to be insignificant (color figure online)

inhibition was only observed at concentrations $>100 \mu \mathrm{M}$, and a low specificity was noted (van der Stel et al. 2020). It is important to note that at least some of the purported cII inhibitors did affect their cognate target, but their impact on overall respiration was attenuated in intact cells, probably by compensation with electrons from cI. This would explain the low or absent neurotoxicity of these compounds.

One reason for different effects of inhibitors may be the complexity of the MRC. Its complexes are huge multi-protein assemblies (cIV, III, and I consist of 13, 22, and 45 protein subunits, respectively), their function can be inhibited at many different sites (Guo et al. 2018). Inhibitors may interfere i) with the binding of the substrate (e.g., NADH) to the complex, ii) with the electron transfer within the complex, or iii) with the transfer of the electrons from the complex to the next substrate (e.g., cI to Q10) (Friedrich et al. 1994; Ino et al. 2003; Okun et al. 1999). The site at which rotenone interacts with cI is known, and cryo-electron microscopy structures are available (Fendel et al. 2008). Recently, it has been shown that deguelin, a rotenone analog, binds to the same site (Troger et al. 2020). For cIII, three inhibitor-binding sites have been identified (Qi, Qo, and NQ site) (Hagras and Stuchebrukhov 2016; Lai et al. 2005), but it is not clear whether more binding sites exist.

\section{Qualitative overview of KE coherence}

We used the data sets from our AOP-guided testing scheme, to compare the concordance across different assays. Our approach was to analyze how far initial KE activation agreed with activation of KE4/AO (assayed in the NeuriTox assay). For this comparison, we considered a fixed concentration is fully in agreement with data from HepG2 cells, where 50\% 
of $50 \mu \mathrm{M}$, as might be used in a screening approach. KE4 was considered to be triggered ("+"), when a compound showed $\geq 25 \%$ effect; otherwise, it was regarded as inactive ("O"). Having set this anchoring point for our comparisons, we checked then whether various other KE assays (for KE1-3) were concordant with KE4 or not. All cI and cIII inhibitors caused neurite toxicity at $50 \mu \mathrm{M}$ (sometimes with accompanying cytotoxicity), and we considered all of them as hits in the KE4 assay. Of the cII inhibitors, thifluzamide was also a hit, while other compounds (carboxin, mepronil, and cyazofamid) were non-hits. All cI inhibitors showed a coherent KE3 assay activity (proteostasis assay) and KE2 assay activity (MMP assay). As test for MRC inhibition, we used LUHMES-based respirometric data (in intact and in permeabilized cells) (Fig. 8, Suppl. Figs. 8 and 10a), and also there, concordant activity (with KE4) was observed. Thus, in this fixed $(50 \mu \mathrm{M})$ concentration (virtual) screen, a high concordance was noted for $\mathrm{cI}$ inhibitors. A more or less similar conclusion could be derived for the cIII inhibitors and for the active cII compound thifluzamide (with some inconsistencies on the KE3 assay). Conclusions on the nonhits were difficult to derive, as effects for these low-potency compounds were often at the borderline of the detection range and of the solubility in the assays. Altogether, this initial comparison draws a consistent picture (at least for positive compounds): it confirms what has been described in the original AOP:3 for rotenone and MPP +, now for more $\mathrm{cI}$ inhibitors and extending it to cIII inhibitors (Suppl. Figure 9). In summary, this initial overview suggested that there is a consistent and concordant activation of the AOP throughout all KE up to the AO. However, this initial overview did not consider potential potency differences and it also did not account for unspecific effects due to cytotoxicity.

Data in support of many AOP have been assembled in such a way, as they had to be derived from many publications and assays, from approaches using different concentration ranges and from publications not always providing full concentration-response data sets. We tested next whether the picture may change, when more comprehensive data are available for a more quantitative comparison.

\section{Synoptic overview of the sensitivities of different assays along the AOP}

Concentration-response data from various assays specifically assembled to probe AOP:3 KEs, allowed us to compare $\mathrm{KE}$ activation (using the respective $\mathrm{EC}_{25}$ concentrations) quantitatively. We used again the neurite toxicity assay (probing KE4/AO) as anchoring point, and considered the ratios of data on KE4/KE3, KE4/KE2, and KE4/KE1 for the subset of compounds tested in all assays.

The KE4/KE3 ratio was mostly in the range of one. From this, one may conclude that the potency of compounds in the KE3 assay is largely similar with that in the neurotoxicity assay, and that, therefore, KE3 assays could be quantitatively predictive for the AO. However, there was one exception and one general caveat. Rotenone was the outlier compound in this comparison, as it affected neurotoxicity (KE4/AO) 100 times more potently than proteostasis (KE3). This effect was not observed for deguelin, which otherwise has many similarities to rotenone. The general caveat is that many of the compounds triggered relatively unspecific cytotoxicity (in the two assays). Since both tests (for KE4 and KE3) are cell-based (LUHMES), the cytotoxicity data are similar, and they result, therefore, in a ratio of 1 . Some of this result is, therefore, not suitable for far-reaching conceptual interpretations (Fig. 9). It also needs to be noted that AOP:3 allows for KE3 to be bypassed, and in the models chosen, there was possibly a direct activation of KE4 by KE2.

The KE4/KE2 ratio was next in the synoptic comparison: cI and cIII inhibitors showed overall quite similar patterns: the mitochondrial membrane potential was mostly impaired at 1-2 orders of magnitude lower concentrations (10-260 times lower) than those found for KE4. This is an important observation for the strategy of using KE assays instead of AO assays. In the context of quantitative hazard assessment, and an in vitro-to-in vivo extrapolation (IVIVE) the predicted equivalent oral doses would differ by 1-2 orders of magnitude, when KE4 or KE2 assay data are used as point-of-departure (POD) (Fig. 9). The difference is unlikely to be explained by differences in free fractions of the test compound in the media of the different assays, as both the LUHMES system and the SH-SY5Y system had very low protein and lipid concentrations (no serum) in the medium (Krebs et al. 2020).

We also examined how the MMP (KE2) assay related to the data on MRC inhibition. As inhibition of cell respiration/MRC complex activity was measured in neurons only for fixed concentrations, we used our previously published data from non-neuronal cells (van der Stel et al. 2020). This assumption of similar biochemical effects on the MRC in various cell types appeared justified, based on the strong concordance between respirometric data derived from HepG 2 cells and RPTEC/TERT1 cells (van der Stel et al. 2020), as well as a good correlation of the concentration-response data for rotenone and deguelin in LUHMES and HepG2 cells (Suppl. Fig. 10a), and the good agreement of the single concentration data on many compounds in neurons, HepG2 and RPTEC cells (van der Stel et al. 2020). The MMP assay was clearly less sensitive for cI inhibitors than the more upstream MRC complex assay. There was some variation for cIII inhibitors, but on average, the sensitivity of this group of test compounds was similar, and the same applied to cII inhibitors (Suppl. Fig. 10b). Thus, the offset of KE assays might depend on the type of compound tested, 


\begin{tabular}{|c|c|c|c|c|c|c|c|}
\hline \multirow[b]{2}{*}{ MoA } & \multirow{2}{*}{$\begin{array}{c}\text { EC25 } \\
\text { KE4 (AO) } \\
\text { Neurite toxicity }\end{array}$} & \multirow{2}{*}{ ID } & \multirow[b]{2}{*}{ Substance } & \multicolumn{4}{|c|}{ Ratios of EC25 } \\
\hline & & & & $\begin{array}{c}\text { KE4/KE3 } \\
\text { proteasomal }\end{array}$ & $\begin{array}{c}\text { KE4/KE2 } \\
\text { MMP }\end{array}$ & $\begin{array}{c}\text { KE4/KE1 } \\
\text { total respiration }\end{array}$ & $\begin{array}{c}\text { KE4/KE1 } \\
\text { complex assay }\end{array}$ \\
\hline \multirow{5}{*}{ 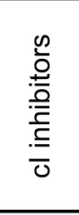 } & \begin{tabular}{|l|}
7.1 \\
\end{tabular} & 19 & Rotenone & 0.01 & 2.1 & 1.3 & 7.9 \\
\hline & 5.4 & 06 & Deguelin & 0.7 & 13 & 32 & 250 \\
\hline & 4.8 & 18 & Pyrimidifen & 1.1 & 21 & 1260 & 15850 \\
\hline & 4.8 & 10 & Fenpyroximate & 0.6 & 20 & 100 & 10000 \\
\hline & 4.7 & 20 & Tebufenpyrad & n.d. & 5.6 & 126 & 1000 \\
\hline \multirow{3}{*}{$\begin{array}{l}\frac{0}{2} \\
. \subseteq \\
\overline{\bar{C}} \\
\end{array}$} & 4.7 & 21 & Thifluzamide & 1.1 & n.a. & $<2$ & 2.5 \\
\hline & 4.1 & 04 & Carboxin & $<0.8$ & 48 & $<8$ & 32 \\
\hline & $<4$ & 14 & Mepronil & $>0.8$ & $>1.8$ & n.a. & $>5.0$ \\
\hline \multirow{5}{*}{$\begin{array}{l}\frac{\dot{0}}{\frac{D}{I}} \\
\overline{\bar{J}}\end{array}$} & 4.8 & 01 & Antimycin A & 1.1 & 257 & 1580 & 1580 \\
\hline & 4.6 & 16 & Pyraclostrobin & 0.7 & 85 & 100 & 400 \\
\hline & 4.5 & 02 & Azoxystrobin & 0.9 & 9.8 & 10.0 & 4.0 \\
\hline & 4.4 & 15 & Picoxystrobin & n.a. & 4.7 & 63 & 31.6 \\
\hline & *4.3 & 05 & Cyazofamid & n.a. & 225 & n.a. & $<5$ \\
\hline
\end{tabular}

Fig. 9 Synoptic overview of the sensitivities of different assays along the AOP. Synoptic overview of the $\mathrm{EC}_{25}$ concentrations (in $-\log [\mathrm{M}])$ of different assays along the AOP for the subset of 14 toxicants which have been characterized in depth. Anchoring point is the EC25 concentration for neurite outgrowth impairment of the NeuriTox test for KE4 (in vitro proxy for the $\mathrm{AO}$ ). $\mathrm{EC}_{25}$ concentrations of other KE assays were displayed as ratio (e.g., KE4/KE1) and

or on the exact target. Notably, the AOP:3 is strictly defined only for cI inhibitors (Terron et al. 2018). For such compounds, sensitivities decreased from KE1 to KE4 by about a $\log$ step per KE.

To further check this, it was interesting to move further along the AOP: the KE4 was compared to the sensitivity of the cellular respiration assay (a proxy for MRC complex inhibition; KE1). It was, for some substances, similar to the KE2 assay, and for some others, it was another ten times more sensitive than the MMP assay. When permeabilized cells were used, a further increase in sensitivity was observed for most cI inhibitors, while cIII inhibitors gave mostly similar results for the two KE1 assays (using intact or permeabilized cells) (Suppl. Fig. 10c; Fig. 9).

In summary, these comparisons of KE assays showed that the general trend was definitely that the concentrations triggering earlier KE were much lower (2-4 orders magnitude) than those triggering later events. This suggests that the AOP has a strong element of counter-regulation and buffering (Leist et al. 2017), so that triggering of an early KE does not always lead to the AO (Fig. 9).

This overall picture was fully confirmed, when we looked at further compounds, for which not all data (e.g., on KE3) are available. Also for the cI inhibitors fenazaquin and pyridaben, the ratio of the NeuriTox assay and the cell respiration assay was 40-60, and the ratio of NeuriTox to the cI assay in permeabilized cells was $\geq 800$. For the additional cIII inhibitors (fenamidone, kresoxim-methyl, and trifloxistrobin), the colored in faint red if $>3$, in red if $>10$ and dark red if $>100$ (i.e., when upstream KE1-3 assay was more sensitive than KE4) and blue if $<0.33$ (i.e., upstream KE3 was less sensitive than KE4) or white for ratios between 3 and 1/3. Note: data on respirometric inhibition were retrieved from HepG2-based assays (van der Stel et al. 2020); n.a.: ratio could not be determined due to low effects; n.d.: not determined. Cyazofamid was in this study not confirmed to be a cIII inhibitor

KE4/KE1 ratio was $\geq 10$ (when cell respiration was considered, and remained in a similar range, when permeabilized cells were used (Suppl. Fig. 11)). Thus, for cI inhibitors, permeabilized cells yielded much lower $\mathrm{EC}_{25}$ values than those obtained in live cells, while for cIII inhibitors, there was no large difference between the data from these two assays. For cII inhibitors, most responses were weak and in a similar concentration range. The only exception was carboxin (KE4/ KE2 ratio: 48 and KE4/KE1 ratio: 32), which behaved like some cIII inhibitors (Fig. 9; Suppl. Fig. 11).

The ranking of the KE sensitivities was not surprising, as it is quite consistent with the AOP concept that initial KE may be activated by lower toxicant concentrations, and that more and more disturbance is required to trigger the final adversity. However, a few studies are available on this phenomenon, and such data are urgently required to improve strategies for quantitative hazard prediction and risk assessment based on integrated approaches to testing and assessment (IATA). Two very important issues are, e.g., in how far early KE assays, or even data from assays related to MIEs can be used for IVIVE. For instance, the ToxCast program has been initially focused on MIE-related assays, and the correlation of these with AO has proven to be low (Thomas et al. 2012). However, in some biological areas, e.g., endocrine signaling, also very good results have been obtained (Browne et al. 2015; Kleinstreuer et al. 2018). An explanation for this may be that some AOP, and certain sets of chemicals show large sensitivity changes for KE activation, 
while others may yield similar, highly consistent PoD for all early and late KE. Also in our study, we see that even within one $\mathrm{AOP}$, the ratio of KE4/KE1 is larger for $\mathrm{cI}$ inhibitors than for cIII inhibitors.

Concerning the different assay sensitivities, it was particularly striking that there appeared to be a clear offset between MRC inhibition tests in intact cells and in permeabilized cells. As all test compounds are quite hydrophobic, the cell permeability is unlikely to account for this difference. For a clear overview of the situation, we compared the data directly to one another (Suppl. Fig. 10d). This overview, generated on the basis of our previously published data (van der Stel et al. 2020), reveals two interesting features: (a) the group of cI inhibitors is rather more potent than the group of cIII inhibitors (with the notable exception of antimycin A); (b) for cIII inhibitors, the whole-cell assay and the cIII assay in permeabilized cells yielded very similar data, while all $\mathrm{cI}$ inhibitors were more potent on the $\mathrm{cI}$ assay than in the whole-cell respiration assay. The cII inhibitors were 2-3 orders of magnitude less potent on their complex, than the cI inhibitors on their cognate target. Such potency differences may play a role. However, also a biological rationale may explain the different behavior: $\mathrm{cI}$ and cII inhibitors may be less potent in cellular assays, as both complexes are redundant and may be bypassed by the respective other one. This is not the case for cIII, which is absolutely necessary and unreplaceable for respiration to take place. In the permeabilized cell assays, the cI and cII were fed electrons from complex-specific donors, and could therefore not be bypassed. Thus, a higher sensitivity might have been observed in this case. Another potential explanation is that the permeabilized cell assay quite clearly addresses KE1 (inhibition of the MRC). The whole-cell assay addresses to some extent general mitochondrial dysfunction, and may therefore be considered as KE2 or as an assay at least partially addressing KE2. As this positions the whole-cell assay somewhat more downstream in the AOP, it may also explain a sensitivity difference (see positioning in Fig. 1).

\section{Conclusions and outlook}

In this study, we set out to explore, (i) whether the AOP:3 (Terron et al. 2018) may be expanded by inclusion of inhibitors of mitochondrial cII and cIII, (ii) whether it could be applied as basis for hazard assessment of industrial and environmental chemicals, such as the set of pesticides chosen here, and (iii) whether rules could be defined on how to use data from KE assays or transcriptome analysis to predict in vivo neurotoxicity. The data generated here lead to a number of important conclusions:

First, the test compounds showed a very heterogeneous behavior, although they were all selected for being classified in the literature as mitochondrial respiratory chain inhibitors. For instance, our MRC complex inhibition data showed that mepronil and capsaicin were misclassified. These compounds are therefore not suitable as positive controls for MRC inhibitors in subsequent studies. However, also bona fide inhibitors showed some unexpected behavior: the cII inhibitors of our study had low potency, and they were difficult to compare to the other compounds. These compounds have been developed to target succinate dehydrogenase of fungi (Lewis et al. 2016), and possibly, there are considerable species differences between the fungal and human protein core subunits. More thorough biochemical studies will be required here. There were many similarities between the behavior of cI and cIII inhibitors, so that an expansion of AOP:3 to cIII inhibition could be justified. However, the situation is complicated by the fact that there was large heterogeneity within the cI and cIII inhibitor groups. For instance, rotenone differed from tebufenpyrad, and antimycin A differed from the strobilurins in their response patterns. It was striking that only some compounds showed a specific neurotoxicity (e.g., rotenone), i.e., a damaging effect on neurites without overall loss of neuronal viability. The mechanistic reasons are at present not well understood, but it is likely that additional targets of the compounds are involved. The potent neurotoxicity of rotenone may be due to additional effects of this compound, e.g., on glycolysis. However, decades of use of this tool compound have not resulted in any data supporting this hypothesis. An alternative explanation could be that rotenone affects other processes that act synergistically with mitochondrial inhibition. There are, for instance, several reports on rotenone's effects on microtubules, affecting, e.g., mitochondrial transport or kinetochore assembly (Brinkley et al. 1974; Cabeza-Arvelaiz and Schiestl 2012; Passmore et al. 2017; Ren et al. 2005; Srivastava and Panda 2007). The largely different potencies and specificities for functional effects within cI inhibitors suggest that modulatory events play an important role in AOP:3, and that each compound may affect them in different ways (allowing for more or less counter-regulation or synergy of events). One potential strategy to follow up on this would be to establish a quantitative AOP, based on system biology principles (feedback loops and modulatory events) and to feed it with more time-dependent data sets. For such work, the compound set used here could be of high interest, as its heterogeneous behavior should be explained by such a model. This is well in line with the intended use of AOP (or AOP networks) for risk assessment: they should not only work for few, "mechanisticallyclean" tool compounds, but for real-life chemicals, with a more "dirty" target profile. Within a more comprehensive risk assessment exercise, also toxicokinetic and biokinetic behavior would be taken into account, and then, the results 
of the KE assays should be related to the in vivo toxicity data. An example of this will be given in an extensive read-across study on the rotenone-deguelin couple to be published within the OECD IATA case study program by the end of 2020.

Second, we found here evidence that the key events of the AOP (or possibly also of other AOP) are so broadly defined that they do not give sufficiently defined guidance on which is the most suitable KE assay to use for a test battery. The KEs, in their presently wide definition (like "mitochondrial dysfunction" or "disturbed proteostasis"), are very useful for descriptive AOPs with the purpose to sort literature data and to give a mechanistic rationale why a certain mechanistic endpoint is linked to an adverse outcome (Leist et al. 2017). For such applications, the large "bins" (combining several biochemical mechanisms in one KE) allow conceptual categories to be formed, that are easy to describe, rationalize, and remember, and that allow broadly applicable rules to be identified (e.g., any type of mitochondrial dysfunction is closely linked to a neurotoxicity hazard). For fully quantitative assessment, the large KE categories are difficult to handle. They may not account sufficiently for the individual and specific properties of each chemical. The exact type of disturbed proteostasis and the exact type of mitochondrial dysfunction may have a large impact on the adverse outcome and on the concentration triggering it. Moreover, the broadly defined KE hardly account for biological subtleties, such as differences of mitochondria from cell type to cell type (Borchard et al. 2018; Kappler et al. 2019). There is also a second issue with broadly defined KE: they allow for mechanistically different types of assays to assess them. Each of these assays may yield different hits, or give varying potencies for a given compound (as shown here e.g., for KE1 assays). It is an important and formidable task for the future to select the best-predictive assays to assess each $\mathrm{KE}$ and/or to understand how data from KE assays should be combined for general hazard assessment.

Third, our synoptic overview clearly showed that the KE assays produce largely (several orders of magnitude) different points-of-departure. The early KEs were more sensitive to test compounds than late $\mathrm{KE} / \mathrm{AO}$. This triggers the question how the KE assays are to be combined for a meaningful in vitro-to-in vivo extrapolations. This situation also implies that not just any KE can be measured if quantitative risk assessment is desired. One may argue that early KE assays are over-sensitive, as their triggering does not always lead to an AO. On the other hand, they could constitute an important alert that can then be followed up with more detailed investigation. In this context, further studies are required on modulating and counter-acting factors, as they may differ from cell to cell or from one human individual to another. Moreover, exposure time may need to be considered, as triggering of early KE may be tolerated by cells (and tissues in vivo) for short periods, but it may result in toxicities after prolonged or repeated exposure.

We addressed here the role of exposure time, by comparing short-term exposure and repeated/prolonged exposure over several days. In this context, it is important that prolonged exposures are experimentally difficult, sometimes even impossible in many test setups. As far as robust test conditions could be established, we did not find major differences between shorter and longer exposures, when neurotoxicity was used as endpoint. For exposures over several weeks, as may be relevant for human pesticide exposure, novel 3D organoids need to be used (Brüll et al. 2020), as conventional cultures have a limited "shelf-life". Another important modulating condition is the metabolic situation. We have found earlier that substitution of glucose in the culture medium by galactose can drastically increase the sensitivity of cells to cI and cIII inhibitors (Delp et al. 2019; van der Stel et al. 2020). This relatively artificial culture environment (brain cells are not exposed to galactose) has been avoided in our study strategy to allow direct transfer of in vitro findings to the in vivo situation. However, we suggest to consider this approach for future studies to span the whole range of potential metabolic situations that may occur in neurons. Under galactose conditions, there would also be considerably less offset in the PoD for various KE.

In summary, the findings of our study suggest that testing along the KE of an AOP can give important guidance on what type of hazard is to be expected. Our data also suggest that the use of KE data for quantitative risk assessment is not straight-forward, and will most likely need to be much more thoroughly explored in many cases. For a qualitative judgment, testing along AOP KEs will be helpful, especially, if a prediction model can be developed that integrates the data from the assays into an overall prediction. Such a process requires many in vivo data to be available for calibration, and it is being explored at present for the skin sensitization assay (Gilmour et al. 2020).

A side aspect of our study is that we explore the use of gene expression data to support KE activation. Although we present here only an initial and superficial analysis, there is already an important finding: the NOEL (or $\mathrm{BMC}_{10}$ ) of gene expression falls within the range of other KE test data. Thus, this omics approach is by no means over-sensitive. This means that it may be possible to define sets of genes that indicate the activation of a KE within a relevant concentration range. One approach to do this is to apply weighted gene co-regulated network (WGCN) analysis (Copple et al. 2019). If this is calibrated in a way to find a threshold of activation that correlates with adversity, WGCN analysis might provide a general method to test for AOP activation. This points to important follow-up work: finding the right time point to assay the transcriptome change, defining the relevant WGCNs, and defining their threshold of adversity. 
The set of compounds studied here may be an important toolset for this approach.

Acknowledgements The Bioimaging Center of the University of Konstanz is acknowledged for providing excellent support and the confocal microscopy instrumentation. We are grateful for experimental support by F. Rudolf and M. Funke.

Funding Open Access funding enabled and organized by Projekt DEAL. This work was supported by the Land-BW (INVITE), the BMBF (Innosystox (moving)), the University of Konstanz, the Deutsche Forschungsgemeinschaft (KoRS-CB), and the Projects from the European Union's Horizon 2020 research and innovation programme EUToxRisk (grant agreement No 681002) and ENDpoiNTs (grant agreement No 825759).

Data availability TempO-Seq data have been deposited as described in methods and supplementary information. Other data are available upon reasonable request.

\section{Compliance with ethical standards}

Conflict of interest The authors declare that there is no conflict of interest.

Open Access This article is licensed under a Creative Commons Attribution 4.0 International License, which permits use, sharing, adaptation, distribution and reproduction in any medium or format, as long as you give appropriate credit to the original author(s) and the source, provide a link to the Creative Commons licence, and indicate if changes were made. The images or other third party material in this article are included in the article's Creative Commons licence, unless indicated otherwise in a credit line to the material. If material is not included in the article's Creative Commons licence and your intended use is not permitted by statutory regulation or exceeds the permitted use, you will need to obtain permission directly from the copyright holder. To view a copy of this licence, visit http://creativecommons.org/licenses/by/4.0/.

\section{References}

Allen TE, Goodman JM, Gutsell S, Russell PJ (2014) Defining molecular initiating events in the adverse outcome pathway framework for risk assessment. Chem Res Toxicol 27(12):2100-2112. https ://doi.org/10.1021/tx500345j

Bal-Price A, Lein PJ, Keil KP et al (2017) Developing and applying the adverse outcome pathway concept for understanding and predicting neurotoxicity. Neurotoxicology 59:240-255. https://doi. org/10.1016/j.neuro.2016.05.010

Bal-Price A, Leist M, Schildknecht S, Tschudi-Monnet F, Paini A, Terron A (2018) Adverse outcome pathway on inhibition of the mitochondrial complex I of nigro-striatal neurons leading to parkinsonian motor deficits. OECD Publishing, Paris. https://doi. org/10.1787/b46c3c00-en

Blacker TS, Duchen MR (2016) Investigating mitochondrial redox state using NADH and NADPH autofluorescence. Free Radic Biol Med 100:53-65. https://doi.org/10.1016/j.freeradbiomed.2016.08.010

Blecha J, Novais SM, Rohlenova K et al (2017) Antioxidant defense in quiescent cells determines selectivity of electron transport chain inhibition-induced cell death. Free Radic Biol Med 112:253-266. https://doi.org/10.1016/j.freeradbiomed.2017.07.033
Blomme EA, Will Y (2016) Toxicology strategies for drug discovery: present and future. Chem Res Toxicol 29(4):473-504. https://doi. org/10.1021/acs.chemrestox.5b00407

Borchard S, Bork F, Rieder T et al (2018) The exceptional sensitivity of brain mitochondria to copper. Toxicol In Vitro 51:11-22. https ://doi.org/10.1016/j.tiv.2018.04.012

Brinkley BR, Barham SS, Barranco SC, Fuller GM (1974) Rotenone inhibition of spindle microtubule assembly in mammalian cells. Exp Cell Res 85(1):41-46. https://doi.org/10.1016/00144827(74)90210-9

Broom AJ, Ambroso J, Brunori G et al (2016) Effects of mid-respiratory chain inhibition on mitochondrial function in vitro and in vivo. Toxicol Res (Camb) 5(1):136-150. https://doi. org/10.1039/c5tx00197h

Browne P, Judson RS, Casey WM, Kleinstreuer NC, Thomas RS (2015) Screening chemicals for estrogen receptor bioactivity using a computational model. Environ Sci Technol 49(14):8804-8814. https://doi.org/10.1021/acs.est.5b02641

Browne P, Noyes PD, Casey WM, Dix DJ (2017) Application of adverse outcome pathways to U.S. EPA's endocrine disruptor screening program. Environ Health Perspect 125(9):096001. https ://doi.org/10.1289/EHP1304

Brüll M, Spreng AS, Gutbier S et al (2020) Incorporation of stem cell-derived astrocytes into neuronal organoids to allow neuroglial interactions in toxicological studies. Altex. https://doi. org/10.14573/altex.1911111

Cabeza-Arvelaiz Y, Schiestl RH (2012) Transcriptome analysis of a rotenone model of parkinsonism reveals complex I-tied and -untied toxicity mechanisms common to neurodegenerative diseases. PLoS ONE 7(9):e44700. https://doi.org/10.1371/journ al.pone. 0044700

Cheung Y-T, Lau WK-W, Yu M-S et al (2009) Effects of all-transretinoic acid on human SH-SY5Y neuroblastoma as in vitro model in neurotoxicity research. NeuroToxicology 30(1):127-135. https ://doi.org/10.1016/j.neuro.2008.11.001

Copple IM, den Hollander W, Callegaro G et al (2019) Characterisation of the NRF2 transcriptional network and its response to chemical insult in primary human hepatocytes: implications for prediction of drug-induced liver injury. Arch Toxicol 93(2):385-399. https ://doi.org/10.1007/s00204-018-2354-1

Daneshian M, Kamp H, Hengstler J, Leist M, van de Water B (2016) Highlight report: launch of a large integrated European in vitro toxicology project: EU-ToxRisk. Arch Toxicol 90(5):1021-1024. https://doi.org/10.1007/s00204-016-1698-7

Delp J, Gutbier S, Cerff M et al (2018a) Stage-specific metabolic features of differentiating neurons: implications for toxicant sensitivity. Toxicol Appl Pharmacol 354:64-80. https://doi.org/10.1016/j. taap.2017.12.013

Delp J, Gutbier S, Klima S et al (2018b) A high-throughput approach to identify specific neurotoxicants/ developmental toxicants in human neuronal cell function assays. Altex. https://doi. org/10.14573/altex.1712182

Delp J, Funke M, Rudolf F et al (2019) Development of a neurotoxicity assay that is tuned to detect mitochondrial toxicants. Arch Toxicol 93(6):1585-1608. https://doi.org/10.1007/s00204-019-02473-y

Delrue N, Sachana M, Sakuratani Y, Gourmelon A, Leinala E, Diderich R (2016) The adverse outcome pathway concept: a basis for developing regulatory decision-making tools. Altern Lab Anim 44(5):417-429

Dreser N, Madjar K, Holzer AK et al (2020) Development of a neural rosette formation assay (RoFA) to identify neurodevelopmental toxicants and to characterize their transcriptome disturbances. Arch Toxicol 94(1):151-171. https://doi.org/10.1007/s00204-01902612-5

Efremova L, Schildknecht S, Adam M et al (2015) Prevention of the degeneration of human dopaminergic neurons in an 
astrocyte co-culture system allowing endogenous drug metabolism. Br J Pharmacol 172(16):4119-4132. https://doi.org/10.1111/ bph.13193

Escher SE, Kamp H, Bennekou SH et al (2019) Towards grouping concepts based on new approach methodologies in chemical hazard assessment: the read-across approach of the EU-ToxRisk project. Arch Toxicol. https://doi.org/10.1007/s00204-019-02591-7

Fendel U, Tocilescu MA, Kerscher S, Brandt U (2008) Exploring the inhibitor binding pocket of respiratory complex I. Biochim Biophys Acta 1777(7-8):660-665. https://doi.org/10.1016/j.bbabi o.2008.04.033

Feng Y, Ma J, Yuan L (2020) beta-Methylphenylalanine exerts neuroprotective effects in a Parkinson's disease model by protecting against tyrosine hydroxylase depletion. J Cell Mol Med. https:// doi.org/10.1111/jcmm.15571

Fessler E, Eckl EM, Schmitt S et al (2020) A pathway coordinated by DELE1 relays mitochondrial stress to the cytosol. Nature 579(7799):433-437. https://doi.org/10.1038/s41586-020-2076-4

Forsby A, Bal-Price AK, Camins A et al (2009) Neuronal in vitro models for the estimation of acute systemic toxicity. Toxicol In Vitro 23(8):1564-1569. https://doi.org/10.1016/j.tiv.2009.07.017

Friedrich T, van Heek P, Leif $\mathrm{H}$ et al (1994) Two binding sites of inhibitors in NADH: ubiquinone oxidoreductase (complex I). Relationship of one site with the ubiquinone-binding site of bacterial glucose:ubiquinone oxidoreductase. Eur J Biochem 219(12):691-698. https://doi.org/10.1111/j.1432-1033.1994.tb19985.x

Gijbels E, Vilas-Boas V, Annaert P, Vanhaecke T, Devisscher L, Vinken M (2020) Robustness testing and optimization of an adverse outcome pathway on cholestatic liver injury. Arch Toxicol. https://doi.org/10.1007/s00204-020-02691-9

Gilmour N, Kern PS, Alepee N et al (2020) Development of a next generation risk assessment framework for the evaluation of skin sensitisation of cosmetic ingredients. Regul Toxicol Pharmacol 116:104721. https://doi.org/10.1016/j.yrtph.2020.104721

Graepel R, Ter Braak B, Escher SE et al (2019) Paradigm shift in safety assessment using new approach methods: the EU-ToxRisk strategy. Curr Opin Toxicol 15:33-39. https://doi.org/10.1016/j. cotox.2019.03.005

Guo R, Gu J, Zong S, Wu M, Yang M (2018) Structure and mechanism of mitochondrial electron transport chain. Biomed J 41(1):9-20. https://doi.org/10.1016/j.bj.2017.12.001

Gustafsson H, Soderdahl T, Jonsson G, Bratteng JO, Forsby A (2004) Insulin-like growth factor type 1 prevents hyperglycemia-induced uncoupling protein 3 down-regulation and oxidative stress. J Neurosci Res 77(2):285-291. https://doi.org/10.1002/jnr.20142

Gustafsson H, Runesson J, Lundqvist J, Lindegren H, Axelsson V, Forsby A (2010) Neurofunctional endpoints assessed in human neuroblastoma SH-SY5Y cells for estimation of acute systemic toxicity. Toxicol Appl Pharmacol 245(2):191-202. https://doi. org/10.1016/j.taap.2010.02.018

Gutbier S, May P, Berthelot S et al (2018a) Major changes of cell function and toxicant sensitivity in cultured cells undergoing mild, quasi-natural genetic drift. Arch Toxicol. https://doi.org/10.1007/ s00204-018-2326-5

Gutbier S, Spreng AS, Delp J et al (2018b) Prevention of neuronal apoptosis by astrocytes through thiol-mediated stress response modulation and accelerated recovery from proteotoxic stress. Cell Death Differ 25(12):2101-2117. https://doi.org/10.1038/s4141 8-018-0229-x

Hagras MA, Stuchebrukhov AA (2016) Novel inhibitors for a novel binding site in respiratory complex III. J Phys Chem B 120(10):2701-2708. https://doi.org/10.1021/acs.jpcb.5b12347

Harischandra DS, Rokad D, Ghaisas S et al (2020) Enhanced differentiation of human dopaminergic neuronal cell model for preclinical translational research in Parkinson's disease. Biochim Biophys
Acta Mol Basis Dis 4:165533. https://doi.org/10.1016/j.bbadi s.2019.165533

Ino T, Nishioka T, Miyoshi H (2003) Characterization of inhibitor binding sites of mitochondrial complex I using fluorescent inhibitor. Biochimica et Biophysica Acta (BBA) 1605(1):15-20. https ://doi.org/10.1016/S0005-2728(03)00060-4

Kappler L, Hoene M, Hu C et al (2019) Linking bioenergetic function of mitochondria to tissue-specific molecular fingerprints. Am J Physiol Endocrinol Metab 317(2):E374-E387. https://doi. org/10.1152/ajpendo.00088.2019

Karreman C, Kranaster P, Leist M (2019) SUIKER: quantification of antigens in cell organelles, neurites and cellular sub-structures by imaging. Altex 36(3):518-520. https://doi.org/10.14573/altex .1906251

Kim SM, Park YJ, Shin MS et al (2017) Acacetin inhibits neuronal cell death induced by 6-hydroxydopamine in cellular Parkinson's disease model. Bioorg Med Chem Lett 27(23):5207-5212. https ://doi.org/10.1016/j.bmcl.2017.10.048

Kleinstreuer NC, Browne P, Chang X et al (2018) Evaluation of androgen assay results using a curated Hershberger database. Reprod Toxicol 81:272-280. https://doi.org/10.1016/j.repro tox.2018.08.017

Kranaster P, Karreman C, Dold J et al (2020) Time and space-resolved quantification of plasma membrane sialylation for measurements of cell function and neurotoxicity. Arch Toxicol 94(2):449-467. https://doi.org/10.1007/s00204-019-02642-z

Krebs A, Nyffeler J, Karreman C et al (2020) Determination of benchmark concentrations and their statistical uncertainty for cytotoxicity test data and functional in vitro assays. Altex 37(1):155-163. https://doi.org/10.14573/altex.1912021

Krug AK, Balmer NV, Matt F, Schonenberger F, Merhof D, Leist M (2013a) Evaluation of a human neurite growth assay as specific screen for developmental neurotoxicants. Arch Toxicol 87(12):2215-2231. https://doi.org/10.1007/s00204-013-1072-y

Krug AK, Kolde R, Gaspar JA et al (2013b) Human embryonic stem cell-derived test systems for developmental neurotoxicity: a transcriptomics approach. Arch Toxicol 87(1):123-143. https://doi. org/10.1007/s00204-012-0967-3

Krug AK, Gutbier S, Zhao L et al (2014) Transcriptional and metabolic adaptation of human neurons to the mitochondrial toxicant MPP(+). Cell Death Dis 5:e1222. https://doi.org/10.1038/cddis .2014 .166

Lai B, Zhang L, Dong LY, Zhu YH, Sun FY, Zheng P (2005) Inhibition of Qi site of mitochondrial complex III with antimycin A decreases persistent and transient sodium currents via reactive oxygen species and protein kinase $\mathrm{C}$ in rat hippocampal CA1 cells. Exp Neurol 194(2):484-494. https://doi.org/10.1016/j.expne urol.2005.03.005

Leist M, Ghallab A, Graepel R et al (2017) Adverse outcome pathways: opportunities, limitations and open questions. Arch Toxicol 91(11):3477-3505. https://doi.org/10.1007/s00204-017-2045-3

Lewis KA, Tzilivakis J, Warner DJ, Green A (2016) An international database for pesticide risk assessments and management. Hum Ecol Risk Assess 22(4):1050-1064. https://doi.org/10.1080/10807 039.2015 .1133242

Lopes FM, Schröder R, Júnior MLCdF et al (2010) Comparison between proliferative and neuron-like SH-SY5Y cells as an in vitro model for Parkinson disease studies. Brain Res 1337:8594. https://doi.org/10.1016/j.brainres.2010.03.102

Love MI, Huber W, Anders S (2014) Moderated estimation of fold change and dispersion for RNA-seq data with DESeq2. Genome Biol 15(12):550. https://doi.org/10.1186/s13059-014-0550-8

Matelski L, Morgan RK, Grodzki AC, Van de Water J, Lein PJ (2020) Effects of cytokines on nuclear factor-kappa B, cell viability, and synaptic connectivity in a human neuronal cell line. Mol Psychiatry. https://doi.org/10.1038/s41380-020-0647-2 
Nordin-Andersson M, Walum E, Kjellstrand P, Forsby A (2003) Acrylamide-induced effects on general and neurospecific cellular functions during exposure and recovery. Cell Biol Toxicol 19(1):43-51

Ockleford C, Adriaanse P, Berny P et al (2017) Investigation into experimental toxicological properties of plant protection products having a potential link to Parkinson's disease and childhood leukaemia $\dagger$. EFSA J 15(3):e04691. https://doi.org/10.2903/j. efsa.2017.4691

Okuda K, Kotake Y, Ohta S (2006) Parkinsonism-preventing activity of 1-methyl-1,2,3,4-tetrahydroisoquinoline derivatives in C57BL mouse in vivo. Biol Pharm Bull 29(7):1401-1403. https://doi. org/10.1248/bpb.29.1401

Okun JG, Lummen P, Brandt U (1999) Three classes of inhibitors share a common binding domain in mitochondrial complex I (NADH:ubiquinone oxidoreductase). J Biol Chem 274(5):26252630. https://doi.org/10.1074/jbc.274.5.2625

Pakrashi S, Chakraborty J, Bandyopadhyay J (2020) Neuroprotective role of quercetin on rotenone-induced toxicity in SH-SY5Y cell line through modulation of apoptotic and autophagic pathways. Neurochem Res 45(8):1962-1973. https://doi.org/10.1007/s1106 4-020-03061-8

Passmore JB, Pinho S, Gomez-Lazaro M, Schrader M (2017) The respiratory chain inhibitor rotenone affects peroxisomal dynamics via its microtubule-destabilising activity. Histochem Cell Biol 148(3):331-341. https://doi.org/10.1007/s00418-017-1577-1

Perron NR, Beeson C, Rohrer B (2013) Early alterations in mitochondrial reserve capacity; a means to predict subsequent photoreceptor cell death. J Bioenerg Biomembr 45(1-2):101-109. https://doi. org/10.1007/s10863-012-9477-5

Pierce SE, Tyson T, Booms A, Prahl J, Coetzee GA (2018) Parkinson's disease genetic risk in a midbrain neuronal cell line. Neurobiol Dis 114:53-64. https://doi.org/10.1016/j.nbd.2018.02.007

Pistollato F, de Gyves EM, Carpi D et al (2020) Assessment of developmental neurotoxicity induced by chemical mixtures using an adverse outcome pathway concept. Environ Health 19(1):1-26

Ren Y, Liu W, Jiang H, Jiang Q, Feng J (2005) Selective vulnerability of dopaminergic neurons to microtubule depolymerization. J Biol Chem 280(40):34105-34112. https://doi.org/10.1074/jbc.M5034 83200

Rich PR (2003) The molecular machinery of Keilin's respiratory chain. Biochem Soc Trans 31(6):1095-1105. https://doi.org/10.1042/ bst0311095

Saxon E, Luchansky SJ, Hang HC, Yu C, Lee SC, Bertozzi CR (2002) Investigating cellular metabolism of synthetic azidosugars with the Staudinger ligation. J Am Chem Soc 124(50):14893-14902. https://doi.org/10.1021/ja027748x

Schildknecht S, Poltl D, Nagel DM et al (2009) Requirement of a dopaminergic neuronal phenotype for toxicity of low concentrations of 1-methyl-4-phenylpyridinium to human cells. Toxicol Appl Pharmacol 241(1):23-35. https://doi.org/10.1016/j.taap.2009.07.027

Schildknecht S, Karreman C, Poltl D et al (2013) Generation of genetically-modified human differentiated cells for toxicological tests and the study of neurodegenerative diseases. Altex 30(4):427444. https://doi.org/10.14573/altex.2013.4.427

Schildknecht S, Pape R, Meiser J et al (2015) Preferential extracellular generation of the active parkinsonian toxin MPP+ by transporterindependent export of the intermediate MPDP+. Antioxid Redox Signal 23(13):1001-1016. https://doi.org/10.1089/ars.2015.6297

Scholz D, Poltl D, Genewsky A et al (2011) Rapid, complete and large-scale generation of post-mitotic neurons from the human LUHMES cell line. J Neurochem 119(5):957-971. https://doi.org /10.1111/j.1471-4159.2011.07255.x

Sherer TB, Richardson JR, Testa CM et al (2007) Mechanism of toxicity of pesticides acting at complex I: relevance to environmental etiologies of Parkinson's disease. J Neurochem 100(6):14691479. https://doi.org/10.1111/j.1471-4159.2006.04333.x

Spinu N, Bal-Price A, Cronin MTD, Enoch SJ, Madden JC, Worth AP (2019) Development and analysis of an adverse outcome pathway network for human neurotoxicity. Arch Toxicol 93(10):27592772. https://doi.org/10.1007/s00204-019-02551-1

Srivastava P, Panda D (2007) Rotenone inhibits mammalian cell proliferation by inhibiting microtubule assembly through tubulin binding. FEBS J 274(18):4788-4801. https://doi.org/10.111 1/j.1742-4658.2007.06004.x

Stiegler NV, Krug AK, Matt F, Leist M (2011) Assessment of chemical-induced impairment of human neurite outgrowth by multiparametric live cell imaging in high-density cultures. Toxicol Sci 121(1):73-87. https://doi.org/10.1093/toxsci/kfr034

Terron A, Bal-Price A, Paini A et al (2018) An adverse outcome pathway for parkinsonian motor deficits associated with mitochondrial complex I inhibition. Arch Toxicol 92(1):41-82. https://doi. org/10.1007/s00204-017-2133-4

Thomas RS, Black MB, Li L et al (2012) A comprehensive statistical analysis of predicting in vivo hazard using high-throughput in vitro screening. Toxicol Sci 128(2):398-417. https://doi. org/10.1093/toxsci/kfs 159

Tilmant K, Gerets H, De Ron P, Hanon E, Bento-Pereira C, Atienzar FA (2018) In vitro screening of cell bioenergetics to assess mitochondrial dysfunction in drug development. Toxicol In Vitro 52:374-383. https://doi.org/10.1016/j.tiv.2018.07.012

Tong Z-B, Hogberg H, Kuo D et al (2017) Characterization of three human cell line models for high-throughput neuronal cytotoxicity screening. J Appl Toxicol 37(2):167-180. https://doi.org/10.1002/ jat.3334

Troger F, Delp J, Funke M et al (2020) Identification of mitochondrial toxicants by combined in silico and in vitro studies-A structurebased view on the adverse outcome pathway. Comput Toxicol 14:100123. https://doi.org/10.1016/j.comtox.2020.100123

van der Bliek AM, Sedensky MM, Morgan PG (2017) Cell Biology of the Mitochondrion. Genetics 207(3):843-871. https://doi. org/10.1534/genetics.117.300262

van der Stel W, Carta G, Eakins J et al (2020) Multiparametric assessment of mitochondrial respiratory inhibition in HepG2 and RPTEC/TERT1 cells using a panel of mitochondrial targeting agrochemicals. Arch Toxicol 94(8):2707-2729. https://doi. org/10.1007/s00204-020-02792-5

Vinken M (2013) The adverse outcome pathway concept: a pragmatic tool in toxicology. Toxicology 312:158-165. https://doi. org/10.1016/j.tox.2013.08.011

Wink S, Hiemstra SW, Huppelschoten S, Klip JE, van de Water B (2018) Dynamic imaging of adaptive stress response pathway activation for prediction of drug induced liver injury. Arch Toxicol 92(5):1797-1814. https://doi.org/10.1007/s00204-018-2178-z

Witt B, Meyer S, Ebert F, Francesconi KA, Schwerdtle T (2017) Toxicity of two classes of arsenolipids and their water-soluble metabolites in human differentiated neurons. Arch Toxicol 91(9):31213134. https://doi.org/10.1007/s00204-017-1933-x

Xie H-r, Hu L-s, Li G-y (2010) SH-SY5Y human neuroblastoma cell line: in vitro cell model of dopaminergic neurons in Parkinson's disease. Chin Med J 123(8):1086-1092. https://doi.org/10.3760/ cma.j.issn.0366-6999.2010.08.021

Yeakley JM, Shepard PJ, Goyena DE, VanSteenhouse HC, McComb JD, Seligmann BE (2017) A trichostatin A expression signature identified by TempO-Seq targeted whole transcriptome profiling. PLoS ONE 12(5):e0178302. https://doi.org/10.1371/journ al.pone. 0178302

Zgheib E, Limonciel A, Jiang X et al (2018) Investigation of Nrf2, AhR and ATF4 activation in toxicogenomic databases. Front Genet 9:429. https://doi.org/10.3389/fgene.2018.00429 
Zhou B (2015) Adverse outcome pathway: framework, application, and challenges in chemical risk assessment. J Environ Sci (China) 35:191-193. https://doi.org/10.1016/j.jes.2015.07.001
Publisher's Note Springer Nature remains neutral with regard to jurisdictional claims in published maps and institutional affiliations.

\section{Authors and Affiliations}

\section{Johannes Delp ${ }^{1,2}$. Andrea Cediel-Ulloa ${ }^{3,10}$ • llinca Suciu ${ }^{1,4}$ (1) Petra Kranaster ${ }^{1,4}$ • Barbara MA van Vugt-Lussenburg ${ }^{5}$. Vesna Munic $\mathrm{Kos}^{3,11}$. Wanda van der Stel ${ }^{6}$. Giada Carta ${ }^{7}$. Susanne Hougaard Bennekou ${ }^{8}$. Paul Jennings ${ }^{7}$. Bob van de Water ${ }^{6} \cdot$ Anna Forsby $^{3,9} \cdot$ Marcel Leist $^{1}$}

1 In Vitro Toxicology and Biomedicine, Department inaugurated by the Doerenkamp-Zbinden Foundation, University of Konstanz, Universitaetsstr. 10, 78464 Konstanz, Germany

2 Cooperative Doctorate College InViTe, University of Konstanz, Konstanz, Germany

3 Swetox, Unit for Toxicological Sciences, Karolinska Institutet, Stockholm, Sweden

4 Konstanz Research School Chemical Biology (KoRS-CB), University of Konstanz, Konstanz, Germany

5 BioDetection Systems BV, Amsterdam, The Netherlands

6 Division of Drug Discovery and Safety, Leiden Academic Centre for Drug Research, Leiden University, Leiden, The Netherlands
7 Division of Molecular and Computational Toxicology, Amsterdam Institute for Molecules, Medicines and Systems, Vrije Universiteit Amsterdam, Amsterdam, Netherlands

8 National Food Institute, Technical University of Denmark (DTU), Lyngby, Denmark

9 Department of Biochemistry and Biophysics, Stockholm University, Stockholm, Sweden

10 Department of Organismal Biology, Uppsala University, Uppsala, Sweden

11 Department of Physiology and Pharmacology, Karolinska Institutet, Stockholm, Sweden 